The author(s) shown below used Federal funds provided by the U.S. Department of Justice and prepared the following final report:

Document Title: Developmental Theory and Battering Incidents: Examining the Relationship between Discrete Offender Groups and Intimate Partner Violence

Author(s): $\quad$ Paul Mazerolle ; Jeffrey Maahs

Document No.: $\quad 198827$

Date Received: January 2003

Award Number: $\quad$ 98-WT-VX-0007

This report has not been published by the U.S. Department of Justice. To provide better customer service, NCJRS has made this Federallyfunded grant final report available electronically in addition to traditional paper copies.

Opinions or points of view expressed are those of the author(s) and do not necessarily reflect the official position or policies of the U.S. Department of Justice. 


\author{
PROPERTY OF \\ National Criminal Justice Reference Service (NCJRS) \\ Box 6000 \\ Rockville, MD 20849-6000
}

\title{
DEVELOPMENTAL THEORY AND BATTERING INCIDENTS: EXAMINING THE RELATIONSHIP BETWEEN DISCRETE OFFENDER GROUPS AND INTIMATE PARTNER VIOLENCE
}

by

\author{
Paul Mazerolle \\ University of Queensland \\ and \\ Jeffrey Maahs \\ University of Minnesota at Duluth
}

Submitted to the National Institute of Justice, June 2002

This research was supported by Grant No. 98-WT-VX-0007 awarded by the National Institute of Justice, Office of Justice Programs, U.S. Department of Justice. Points of view in this document are those of the authors and do not necessarily represent the official position or policies of the

U.S. Department of Justice

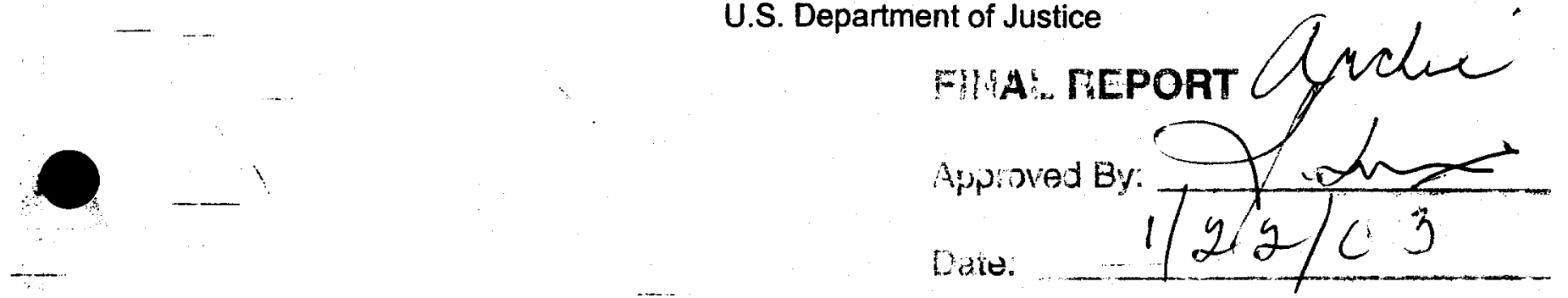




\section{TABLE OF CONTENTS}

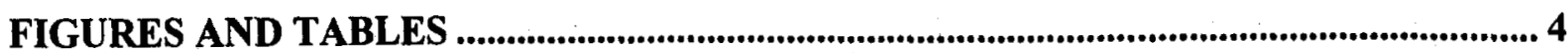

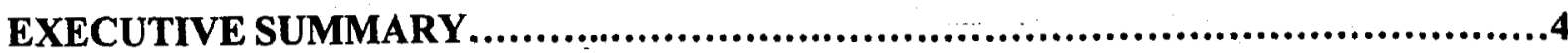

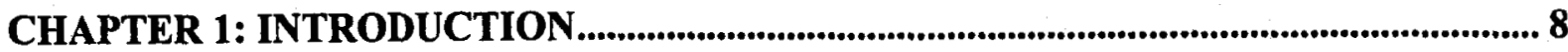

CHAPTER 2: APPLYING MOFFITT'S DEVELOPMENTAL THEORY TO INTIMATE

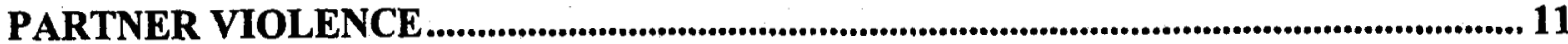

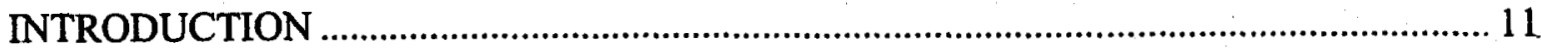

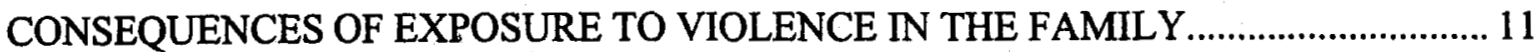

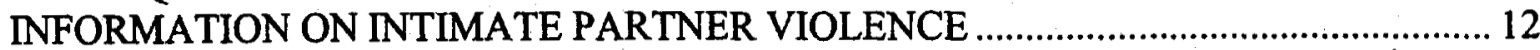

DEVELOPMENTAL THEORY AND INTIMATE PARTNER VIOLENCE .................... 15

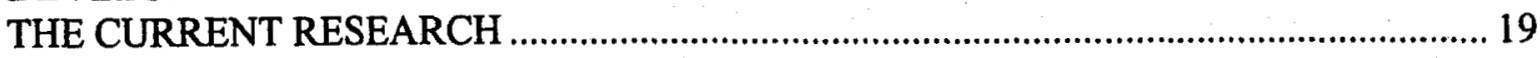

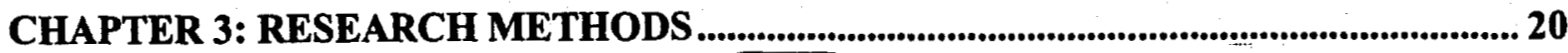

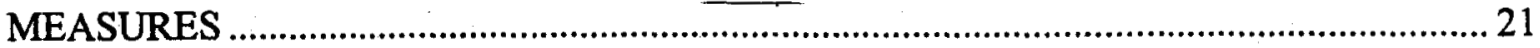

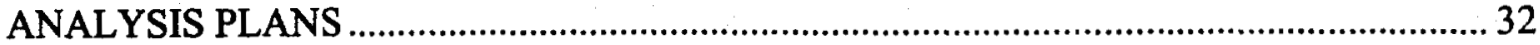

CHAPTER 4: EXAMINING DISCRETE OFFENDING GROUPS ..................................... 36

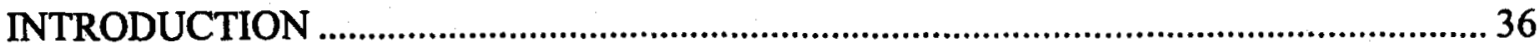

PREVALENCE OF EARLY ONSET OFFENDERS IN THE SAMPLE.............................. 36

RELATIONSHIPS BETWEEN EARLY ONSET STATUS AND EARLY LIFE EVENTS . 37

CHARACTERISTICS ASSOCIATED WITH LIFE-COURSE PERSISTENCE:

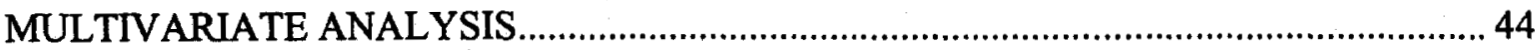

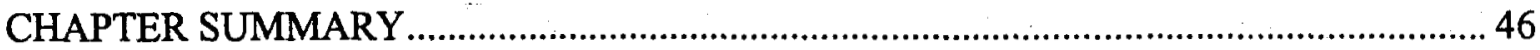

CHAPTER 5: DISCRETE OFFENDER GROUPS, NEGATIVE LIFE OUTCOMES, AND

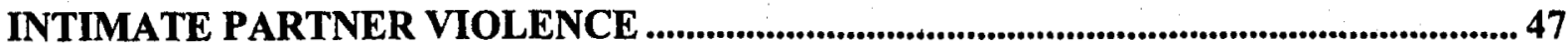

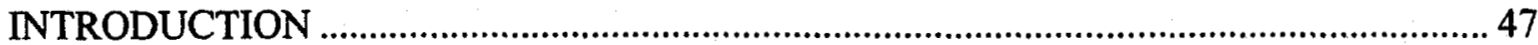

-LIFE OUTCOMES FOR LIFE-COURSE PERSISTENT_OFFENDERS ........................... 47

BASELINE RELATIONSHIPS BETWEEN DISCRETE OFFENDING GROUPS AND

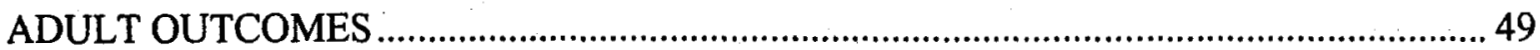

MULTIVARIATE ANALYSIS OF INTIMATE PARTNER VIOLENCE ........................... 54

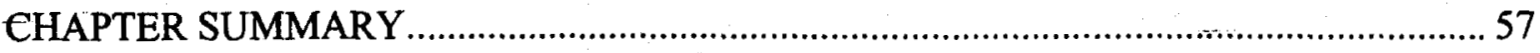




\section{CHAPTER 6: CHILDHOOD EXPOSURE TO VIOLENCE: COMPARING THE EFFECTS OF CHILD ABUSE AND OBSERVING PARENTAL VIOLENCE ON}

NEGATIVE LIFE OUTCOMES.

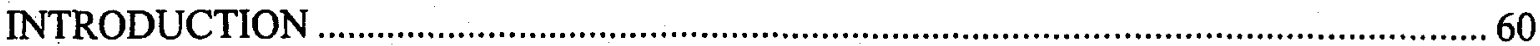

EFFECTS OF EXPOSURE TO VIOLENCE ON NEGATIVE LIFE OUTCOMES ............. 62 COMPARING THE EFFECTS OF PHYSICAL CHILD ABUSE AND OBSERVING FAMILY VIOLENCE INTIMATE PARTNER VIOLENCE: MULTIVARIATE ANALYSES

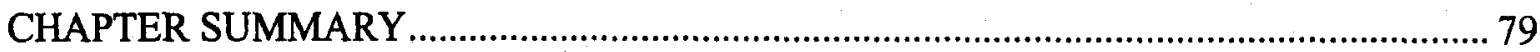

CHAPTER 7: DISCUSSION AND CONCLUSION...................................79

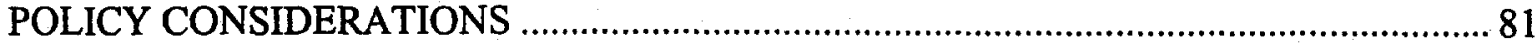

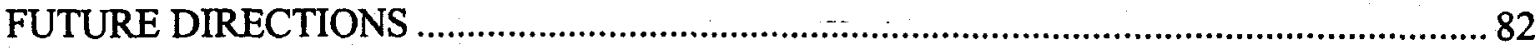

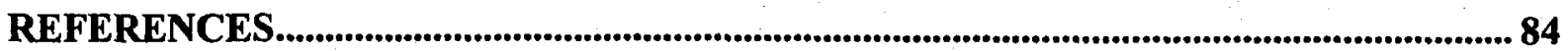

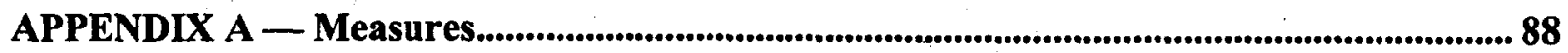

APPENDIX B - Agreement Between Parolee's and Their Partners Using the Conflict Tactics Scale for Violence in the Past Three Months ........................................................... 92 


\section{FIGURES AND TABLES}

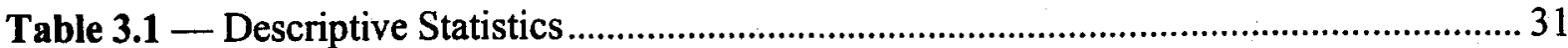

Table 3.1 Continued — Descriptive Statistics..................................................................... 32

Table 4.1 - Bivariate Relationships Between Early Onset Status and Theoretically Relevant

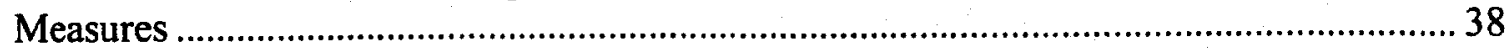

Figure 4.1 - The Relationship Between Negative Life Events and LCP Status ...................... 40

Figure 4.2 - The Relationship Between Mother and Father Figure's Alcohol Related Problems

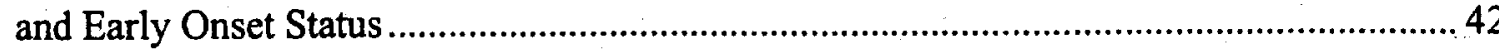

Figure 4.3 - The Relationship Between Family Violence and LCP Status ...............................43.

Table 4.2 - Logistic Regression Predicting LCP Status .................................................... 45

Figure 5.1 - The Relationship Between LCP Status and Lifetime Alcohol Problems ............ 52

Figure 5.2 - The Relationship Between LCP Status and Illicit Drug Use ............................... 52

Figure 5.3 - The Relationship Between LCP Status and Self-Reperted Violence ................... 52

Figure 5.4 - The Relationship Between LCP Status and Intimate Partner Violence................. 53

Table 5.1 - Poisson Regression Models Predicting Intimate Partner Violence In the Year Prior

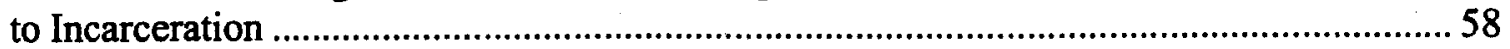

Table 5.2 - Poisson Regression Models Predicting Intimate Partner Violence within Three

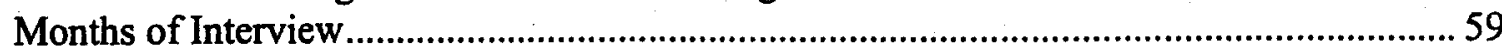

Figure 6.1 - The Relationship Between Childhood Exposure to Violence and Early Onset of

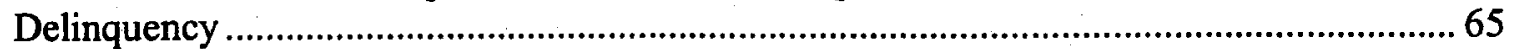

Figure 6.2 - The Relationship Between Childhood Exposure to Violence and Lifetime Alcohol

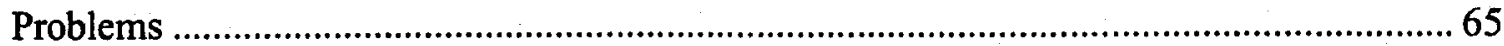

Figure 6.3 - The Relationship Between Childhood Exposure to Violence and Number of

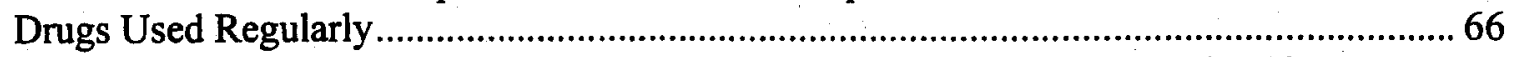

Figure 6.4 - The Relationship Between Childhood Exposure to Violence and Self-Reported Violent Crime

Figure 6.5 - The Relationship Between Childhood Exposure to Violence and Intimate Partner

Violence.............................................................................69

Table 6.1 - Poisson regression models predicting intimate partner violence in the year prior to

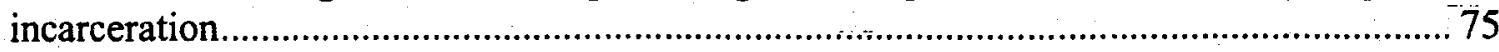

Figure 6.6 - The Relationship Between Different Types of Childhood Exposure to Violence

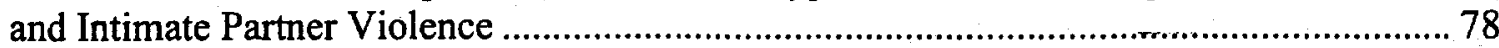




\section{EXECUTIVE SUMMARY}

A pressing public policy concern in America is the unacceptably high levels of violence among intimate partners such as married or co-habitating couples. Statistics revealing that the leading cause of serious injury for women in the United States is violence perpetrated by their male companions (Stark and Flitcraft, 1992) attests to the significance of this issue. While past theory and research on intimate partner violence has revealed a wealth of information, a recent recommendation from the National Research Councils' Panel of Research on Violence against Women (Crowell and Burgess, 1996:90) identifies the need to examine intimate partner violence from a developmental and life-span perspective. In the current project, we propose to incorporate the recent developmental theory by Moffitt (1993) to help understand incidents of intimate partner violence.

This project uses data collected from a sample of parolees and their spouses in Buffalo, New York in 1987 (Blane, Miller, and Leonard, 1987), to examine relationships between discrete offender groups (e.g. high rate versus low rate offenders) consistent with Moffitt's theory and subsequent intimate partner violence. The research also examines a range of factors that are expected to be associated with intimate partner violence, including alcohol and substance abuse history, early exposure and experiences with violence, as well as a range of psychological and social factors. Key research questions in the study involve: assessing the predictors of early onset to delinquency; the negative consequences associated with exposure to violence in the family during childhood; whether high rate, life-course persistent offenders are more likely to become perpetrators of intimate partner violence in adulthood; and whether there are different effects of observing partner violence as opposed to being physically abused during childhood on the likelihood of perpetrating partner violence in adulthood.

The results of the study include:

- Life course persistent offenders (i.e. more serious, high rate offenders) experience higher levels of social adversity while growing up, involving increased family disruption, having parents with alcohol problems, and higher levels of exposure to violence in the home as compared to non-LCP offenders

- Life course persistent offenders experience more negative life outcomes than non-LCP offenders including greater lifetime alcohol problems, more illicit drug use, higher levels of violent crime, and highēr levels of intimate partner violence in adulthood.

- Early exposure to violence during childhood is associated with a range of negative outcomes, such as early delinquent onset, alcohol problems, and violence.

- The effects of early exposure to violence during childhood on perpetrating intimate partner violence in adulthood are influenced primarily by observing inter-parental violence as opposed to being physically abused. 
- Results from Poisson regression models reveals that life course persistent offenders have a higher probability of intimate partner violence in adulthood, net of other influences.

Additional salient influences predicting partner violence include drug and alcohol abuse.

Overall, the results from this study highlight the range of negative consequences associated with early exposure to violence during childhood, the differences between the effects of observing inter-parental violence as opposed to being physically abused during childhood on adult perpetration in intimate partner violence, and the increased probability of engaging in intimate partner violence for serious, life course persistent offenders.

The results illustrate that interventions targeted at serious offenders can have additional benefits, such as reducing the likelihood of intimate partner violence. 


\section{CHAPTER 1: INTRODUCTION}

Domestic violence is a serious public health concern in America. ${ }^{1}$ Estimates from the National Crime Victimization Survey expects that as many as 2 million women are beaten by their partners annually (Bachman and Saltzman, 1995). Moreover, the leading cause of serious injury for women in the United States is violence perpetrated by their male companions (Stark and Flitcraft, 1992). While annual estimates of male perpetrated violence among married and co-habitating couples have been as high as $14 \%$, lifetime prevalence rates reveal that approximately one in four married or co-habitating women are assaulted by their partners (Johnson and Sacco, 1995; Hanson et al., 1997). Thus, the shear prevalence of intimate partner violence as well as its associated problems are serious and warrant attention from academicians, public policy makers, and concerned citizens alike.

Evidence consistently reveals that early exposure to violence in the family has several negative consequences for children (Loeber and Stouthamer-Loeber, 1986; Widom, 1989a; Smith and Thornberry, 1995; Singer et al. 1999). For example, early exposure to violence has been linked to depression (Cerezo-Jimenez and Frias, 1994), post traumatic stress disorders (Famularo et al., 1994), substance abuse (Duncan et al., 1996), delinquency (Smith and Thornberry, 1995; Widom, 1989b), and a host of other internalizing and externalizing problems. In addition to these negative outcomes, early exposure to violence has been linked with an

\footnotetext{
'Domestic violence includes a range of violent behavior occurring within the familial context, such as child maltreatment and spousal assault. Our focus in the current project is on male perpetrated violence directed toward intimate female partners (married or cohabitating). Any references to domestic violence in the current report refers to our more specific focus on intimate partner violence by men directed toward women.
} 
increase in arrests for violence in adulthood (Rivera and Widom, 1990) as well as an increased likelihood of violence in adult relationships (Cappell and Heiner, 1990; Carter et al., 1988).

While a number of different theoretical perspectives have informed our understanding of intimate partner violence in the past, the National Research Councils ${ }^{\perp}$ Panel of Research on Violence against Women (1996:90) identified the need to examine this behavior from a developmental or life-span perspective. Recognizing the value of recent developmental theories of crime causation (Moffitt, 1993; Patterson, DeBaryshe, and Ramsey, 1989; Thomberry, 1987) and the fact that few attempts have been made at applying developmental theories to domestic violence, this project examines the developmental theory by Moffitt (1993) to help understand incidents of intimate partner violence.

Collectively, this project examines at least four inter-related issues. First, we examine the characteristics associated with high criminal propensity, which is indexed by early onset to delinquency. Second, in exploring the consequences of early exposure to violence, we examine relationships between cumulative exposure to violence in childhood with a series of negative life outcomes including early delinquent participation, violence, alcohol abuse, and illicit drug use. Third, we examine whether being exposed to physical child abuse as opposed to observing interparental violence in one's family of origin has different consequences on the likelihood of intimate partner violence. Fourth, we apply a recent developmental theory of offending behavior (Moffitt, 1993) to male-perpetrated intimate partner violence to assess whether more serious offenders have a higher likelihood of becoming perpetrators of partner violence. This project reveals important information about both the consequences of early exposure to violence during 
childhood as well as developmental antecedents involved with serious violence among intimate partners.

This final report is divided into seven chapters. Chapter 2 describes relevant literature on intimate partner violence and discusses Moffitt's developmental taxonomy and how it relates to male-perpetrated intimate partner violence. Chapter 3 presents the research methods employed in the study including a description of the sample and measures used, as well as the descriptive statistics for the sample. Information on the relationships between various measures and early delinquent participation-- a key feature of Moffitt's theory-- are presented in Chapter 4. Results examining the multivariate relationships linking Moffitt's developmental theory and intimate partner violence are reported in Chapter 5. In a series of models, we assess whether there are differences in the likelihood of intimate partner violence across discrete groups of offenders, drawn from Moffitt's developmental theory. In Chapter, 6 , information on a range of the consequences associated with early exposure to violence in the family is presented. In addition, a series of multivariate models are presented which assess whether exposure to physical abuse during childhood as opposed to observing violence (i.e. inter-parental conflict) between parents have unique effects on perpetration in intimate partner violence. Finally, Chapter 7 presents a discussion and conclusion that identifies the theoretical and public policy implications arising from the research. 


\section{CHAPTER 2: APPLYING MOFFITT'S DEVELOPMENTAL THEORY TO INTIMATE PARTNER VIOLENCE}

\section{INTRODUCTION}

In this chapter, previous literature on the consequences of exposure to violence in the home during childhood, as well as past research on intimate partner violence will be discussed. Additionally, a discussion of Moffitt's developmental theory (1993), including how the theory is related to intimate partner violence will be presented. The chapter will also identify some of the key areas of research to be examined in this report.

\section{CONSEQUENCES OF EXPOSIJRE TO VIOLENCE IN THE FAMILY}

A wealth of past research has uncovered a number of deleterious consequences that are related to childhood exposure to violence (Thornberry, 1994; Smith and Thornberry, 1995;

Dodge et al., 1990; Widom, 1989a; Moffitt and Caspi, 1998; Singer et al., 1999; Duncan et al., 1996; Malinosky-Rummell and Hansen, 1993). Exposure to physical child maltreatment has been associated with a host of negative outcomes including depression (Duncan et al 1996), running away (Kurtz et al., 1991; Kaufman and Spatz-Widom, 1999), substance abuse (Duncan et al., 1996), delinquency (Widom 1989b, Smith and Thornberry, 1995, Z̈ingraff et al . 1993), and violent crime (Singer et al, 1999; Thomberry, 1994; Rivera and Widom, 1990). Additionally, observing parental violence during childhood is problematic and has been linked with increases in violence (Spaccerelli et al., 1995; Thornberry, 1994) as well as an increased 
likelihood of intimate partner violence (Choice et al., 1995; Cappell and Heiner, 1990; Carter et al., 1988; Hotaling and Sugarman, 1986).

Some research has examined the consequences of the combined impact of witnessing partner violence and experiencing maltreatment. For example, research by Hughes and colleagues (1989) finds that children who witness partner violence and are abused have many more problems than youth in non-violent or less violent comparison groups. Additionally, Hotaling and colleagues (1989) find that children who experience multiple exposure to violence in the family (witness parental violence and experience abuse) are six times more likely than children from non-violent homes to assault other children.

Given the range of negative consequences associated with childhood exposure to different types of violence, there is a need to examine whether exposure to specific types of violent experiences give rise to specific problems later in adulthood. Moreover, it remains unclear the extent to which different levels of exposure to violence in childhood impact later life outcomes, such as intimate partner violence.

\section{INFORMATION ON INTIMATE PARTNER VIOLENCE}

A wealth of information on the nature and dimensions of intimate partner violence has emerged over the past fifteen years (Crowell and Burgess, 1996; Gelles and Loseke,1993; Straus and Gelles, 1990). More specifically, a number of factors have been identified to help distinguish men who batter their spouses and partners from those who do not. For example, past research reveals that batterers are more likely to: emerge from patriarchal families emphasizing traditional gender roles (Fagot et al., 1988), exhibit less responsibility for their actions (Bamett and Hamberger, 1992), have limited education (Hotaling and Sugarman, 1986) and have more general antisocial orientations (Simons et al., 1995) than men who do not batter their spouses and 
partners. Moreover, research finds that income, alcohol abuse, and perceptions of marital relationship quality are related to intimate partner violence even after controlling for psychological characteristics such as, anxiety, paranoia, and hostility as well as social influences such as negative life events and social support (McKenry et al., 1995).

Previous reviews on partner violence have focused on how specific risk markers increase the likelihood of assaultive behavior. For example, research by Hotaling and Sugarman (1986) revealed eight characteristics which represent risk markers for partner violence including:

- witnessing parental violence as a child or teen;

- sexual aggression toward wife/partner;

- violence toward children;

- working class occupational status;

- low income;

- low educational level;

- lack of assertiveness;

- excessive alcohol usage.

Some of the more recent evidence on spouse and partner abuse reveals that batterers do not necessarily comprise one homogeneous group. For example, a typology developed by Saunders (1992) reveals three distinct groups of batterers: family only aggressors, generalized aggressors, and emotionally volatile aggressors. Using data collected from 165 men who were being assessed for participation in a treatment program for batterers, Saunders found differences between types of batterers on measures gauging attitudes toward women and violence, anger, marital satisfaction and jealousy, as well as abuse in childhood. Additionally, using cluster analytical techniques, Saunders found that predictors of battering accounted for $90 \%$ of the variance in the battering typologies. 
Perhaps the most comprehensive research to date on the issue of heterogeneity among battering behavior has recently been reported by Holtzworth-Munroe and Stuart (1994). In an extensive review of previous research, the authors found good evidence for there being three distinct categories of male battering behavior including: family only, dysphoric/borderline, and generally violent/antisocial. According to the authors, a number of different characteristics distinguish batterers across the groups. For example, the family only type exhibit high levels of dependence on their partners, whereas the dysphoric/borderline types often have experienced child abuse. Additionally, the family only type are expected to engage in the least severe forms of partner violence and their violent behavior should be limited to within the family unit. According to Holtzworth-Munroe and Stuart, the family only type should account for the majority of men who assault their intimate partners, representing approximately $50 \%$ of all batterers.

The dysphoric/borderline type by contrast, should engage in more moderate levels of intimate partner violence. Although the majority of their violent activity should occur within the home environment, they should also have a history of criminal activity. Some of the defining characteristics of these men include their psychological problems and emotional distress as well as problems with alcohol and substance abuse. According to Holtzworth-Munroe and Stuart, dysphoric/borderline batterers should comprise $25 \%$ of batterer samples.

Their final typology, the generally violent/antisocial batterers engage in moderate to severe levels of intimate partner violence. These men should also engage in other forms of abusive behavior, such as psychological and sexual abuse. Moreover, these men are expected to engage in violence outside of the home environment and to have rather lengthy histories of criminal activity. Other defining features of the generally violent/antisocial batterers include problems with drugs and alcohol was well as antisocial personality traits. According to 
Holtzworth-Munroe and Stuart, this typology of assaultive men should comprise $25 \%$ of batterer samples.

These typologies of battering not only help researchers identify the causes of partner violence, but they also have the potential to improve treatment programs so they can be better specified to address the specific needs of men who assault their intimate partners. Clearly, more research is needed to firmly establish the empirical basis for typologies of battering behavior. Additionally, comparisons need to be undertaken with typologies of offending behavior from the more general criminological literature.

\section{DEVELOPMENTAL THEORY AND INTIMATE PARTNER VIOLENCE}

Developmental theories offering dynamic explanations of criminal behavior have emerged in recent years, yet few attempts have focused on understanding intimate partner violence from a developmental perspective (see Holtzworth-Munroe and Stuart, 1994 for an exception). And despite the fact that the criminological and family violence literatures have emerged along two fairly distinctive tracts, there are good reasons for examining theories across disciplines. For example, theories developed for understanding more general forms of criminal activity may aid in an understanding of partner violence and by implication expand the scope of such theories. Additionally, there are logical reasons to expect spousal assault to be effected by forces or factors that influence deviant behavior more generally (e.g., impulsivity, low self control, weak moral constraints, etc.). Applying developmental theories in particular, present unique opportunities for understanding how crime and violence unfold over the lifecourse and how specific events alter trajectories and offending pathways (Laub and Sampson, 1993;

Thomberry, 1997). Further, it is increasingly important to examine the ongoing consequences of early delinquent participation and persistence in offending behavior to examine how these processes are related and have consequences for other forms of antisocial behavior, such as 
partner violence. The theoretical work by Moffitt (1993) presents an opportunity to examine some of these aforementioned issues by applying her different offending typologies to the intimate partner violence context.

Moffitt's theory identifies two developmental typologies of offending behavior: lifecourse persistent and adolescent-limited offending. The life-course persistent pattern of offending identifies how the unfortunate association of neuropsychological deficits present at birth and unhealthy environmental conditions (e.g., limited resources, poor parenting habits, etc.) combine to produce individuals who are anti-social and under-controlled as children, persistently impulsive, and subsequently at risk for early initiation into delinquent conduct. The life-course persister exhibits fairly stable behavioral patterns, tends not to be especially reflective and verbal, and embraces a wide range of behavioral patterns including diverse offending activities. In short, according to Moffitt's theory, life-course persistent offenders will exhibit substantial versatility in offending including perhaps partner violence.

Moffitt's other typology involves what she labels adolescent-limited offending. This typology captures both the upsurge of delinquency during adolescence as well as the remarkable downswing soon thereafter as adulthood approaches. According to Moffitt, the primarycausal forces leading to adolescent-limited offending include the expanding maturity gap (between biological and social development) which can foster feelings of strain and frustration that become problematic when adolescents are exposed to criminogenic behavior patterns through delinquent peer affiliations. Thus, this typology of offending is characterized as adaptive compared to the maladaptive dimensions of life-course persistent offending. Moreover, according to Moffitt's theory adolescent-limited offenders should exhibit less variety and - stability in their offending behavior. Consequently, adolescent-limited offenders should be less likely than life-course persisters to engage in assaultive behavior against their partners. 
Our expectations from Moffitt's theory, therefore, lead us to anticipate that life-course persistent offenders are more at risk for intimate partner violence than other offender groups including adolescent-limited offenders. We expect that the accumulating consequences of antisocial behavior over time will increase the likelihood of participation in intimate partner violence for life-course persistent offenders. This does not imply that adolescent-limited offenders will necessarily be immune to partner violence. However, their moderate levels of social, interpersonal, and academic skills should reduce their likelihood of engaging in this behavior relative to their more antisocial counterparts (i.e. life-course persisters). Moffitt's theoretical model identifies how individual-level deficits present at birth combine with environment risk factors such as, weak parenting skills to compromise effective socialization processes.

\section{Our conceptual model tinking Moffitt's life-course persistent offending typology with} intimate partner violence identifies how the combination of violence in one's home of origin, coupled with exposure to negative life events (such as, parental separations, family moves) increases the probability of early delinquent participation. On the basis of Moffitt's theory, we expect that early delinquent participation (which is a proxy for life-course persistent offending-group status) will be related to subsequent violent criminatity through adolescence and into adulthood. These relationships are consistent with previous research findings that early onset is related to frequent, lengthy, serious and violent criminal activity (Loeber and Dishion, 1983; Loeber, 1982, 1988; LeBlanc, 1990; Patterson and Yoerger, 1993; Tolan, 1987).

The life-course persistent offender depicted by Moffitt (1993) is expected to be at risk for problems in interpersonal relationship functioning (e.g., more separations, divorces and adversity in relationships) as well as having difficulties achieving success through legitimate occupational pursuits. Moreover, life-course persistent offenders are expected to have more serious alcohol usage problems, which are expected to contribute to partner violence (Kaufman Kantor and Straus, 1989; Kaufman Kantor, 1993; Dutton, 1988; Gondolf, 1988). 
Overall, we expect Moffitt's life-course persistent offender to be at risk for engaging in partner violence and we anticipate these relationships to be even more pronounced when violence in the home of origin is considered. Violence in the home of origin is expected to function as a training ground for internalizing and embracing violence as an appropriate means by which to control others or resolve disputes. Coupled with deficits in social functioning, lifecourse persistent offenders (who are exposed to violence) would not be well equipped to avoid violence in their interpersonal relationships with intimate others.

In Moffitt's recent research using data from the Dunedin Multidisciplinary Health and Development Study (Moffitt and Caspi, 1999), a strong relationship between having a conviction for crime, especially a violent crime and intimate partner violence was observed among the age 21 cohort. The results revealed individuals convicted of a criminal offense were twice as likely to report intimate partner violence when compared to respondents without criminal convictions. The data revealed that $38 \%$ of respondents with a criminal conviction at age 21 reported physical violence against a partner, compared with $18 \%$ of respondents without a criminal conviction. The comparison was even stronger for respondents with a conviction for violent crime ( $50 \%$ reporting physical violence against a partner vs $20 \%$ ).

In a subsequent analysis, Moffitt and colleagues (2000) report some overlap between the correlates of general offending and intimate partner violence, but also some important differences between the outcomes. Their analysis showed that partner abuse and general offending behavior had high levels of negative emotionality in common, but differed on levels of low self-control, which appeared more relevant for explaining crime, as opposed to partner abuse. Overall, their results suggest that partner abuse and general crime represent distinct, but moderately correlated constructs.

The research undertaken in the current study will extend research on Moffitt's theory to further examine the linkages between general offending and intimate partner violence. 


\section{THE CURRENT RESEARCH}

In the current project, we examine a number of research questions that allow us to explore the linkages between Moffitt's developmental theory of offending behavior and intimate partner violence. More specifically, we will address the following general areas of research enquiry:

- The characteristics associated with early delinquent participation and the differences between high propensity and low propensity offenders.

- Whether high propensity offenders (i.e. life-course persisters) are more likely than lower propensity offenders to engage in intimate partner violence during adulthood.

- The varied consequences of early exposure to violence in the family as well as whether higher levels of exposure to violence are associated with higher levels of negative outcomes.

- Whether exposure to physical child abuse during childhood as opposed to observing partner violence during childhood has differential effects on perpetrating intimate partner violence during adulthood. 


\section{CHAPTER 3: RESEARCH METHODS}

The data used in this project are drawn from a previous study on the interrelationships between substance abuse, and criminal and domestic violence across three generations (Blane et al, 1994). Specifically, subjects were drawn from a stratified random sample of all parolees residing in the greater Buffalo, New York, area between January 1987 and June $1987 .^{2}$ Of the 259 subjects sampled, $194(75 \%)$ agreed to participate and were interviewed. The parolees who chose not to participate in the study did not differ from parolees participating on a range of measures including age, race, marital status, criminal history, drug/alcohol problems, or instant offense variables. However, one difference was observed in that parolees who refused to be the interviewed were more likely to have emotional problems.

Criminal history information was gathered from each respondent's pre-sentence investigation report. Information collected in the interview covered several domains, including self-reported delinquency and crime, early exposure to different types of family violence, and drug/alcohol use. Additionally, revised versions of the Conflict Tactics Scale (Straus, 1979, hereinafter CTS) were used to gauge varying forms of intimate partner violence as well as exposure to physical child abuse and observing inter-parental violence in childhood.

\footnotetext{
${ }^{2}$ In selecting the sample, the parolees were stratified into violent and non-violent groups based on their last conviction offense. Parolees whose last conviction offense could not be clearly classified as either violent or nonviolent (e.g. DWI, reckless endangerment) were excluded from the sample. While this sample selection criteria suggests that offenders may specialize in particular types of crime, such as violence, a wealth of information reveals that offenders, especially serious offenders, exhibit versatile offending patterns (Wolfgang et al., 1972; Tracy and Kempf-Leonard, 1996; Hindelang, 1971). While the current project does not examine this issue, it is important to acknowledge that the sample selection criteria may impose violent and non-violent classifications upon parolees in the sample.
} 
To assess intimate partner violence, the CTS was given to parolees who were either in a relationship in the year prior to their most recent incarceration or in the three prior months prior to being interviewed. Those parolees who were in relationships during both time periods were given a separate CTS schedule for each relationship.

The sub-sample of the larger study used for the present analyses consists of 180 male parolees, of whom 111 were in a relationship in the year prior to their incarceration, and 107 were in a relationship in the three months prior to the interview. Further, 78 parolees were in relationships during both time periods. Female parolees $(\mathrm{N}=14)$ were excluded from the analysis due to their small group size.

Individuals who were not in a relationship during the assessment windows (three months prior to interview, or year prior to prison) were not given the CTS. This raises issues regarding how to treat subjects who were not in a relationship. This issue is addressed fully in at the end of this chapter.

\section{MEASURES}

Descriptive statistics for all measures used in the report are reported in Table 1. Additionally, specific items and scale construction techniques are detailed in Appendix A. Some measures are used as both dependent and independent variables in different sections of the report. Accordingly, the variables are organized into four conceptual categories, (a) early life events, (b) parolee self-reported deviance, (c) psychological measures, and (d) demographic characteristics. 


\section{Early Life Events}

Early life events include measures that tap into the childhood experiences of the respondents, such as their exposure to violence within the family, parental drinking, and other negative experiences. These measures are employed in the analysis to predict the early onset of delinquency, and later to predict intimate partner violence.

\section{Exposure to Violence}

Childhood exposure to violence was assessed using revised versions of the Conflict Tactics Scale that gauged inter-parental violence and physical child abuse. More specifically, for each respondent the measures assessed (a) each of their parental figures' physical violence toward them as a child; and (b) each of their parental figures' violence towards each other. ${ }^{3}$ For each of these relationships, subjects were asked to report the frequency of twelve specific acts of violence, ranging from pushing or shoving to beating and choking, that they had observed or experienced as a child (see specific items listed in Appendix A). Because these reports were retrospective and the response categories were somewhat ambiguous, the specific items were dichotomized and summed to form an index. ${ }^{4}$ This practice, which yields a "variety index," represents a more accurate gauge for measuring self-reports of past experiences with violence.

\footnotetext{
${ }^{3}$ Information was not limited to biological parents as respondents also reported the activities of their step-parents.
}

${ }^{4}$ The original response categories were: never, happened/frequency unknown, once or twice, several times, about once a month, about once a week or more. 


\section{Child Abuse}

The physical child abuse measure was created by summing respondents' reports of whether their mother, father, or step-parent committed any of twelve specific violent acts toward them. The specific acts ranged in severity from slapped, pushed, grabbed, or shoved to very serious events such as beat up, choked, or used knife or gun. All of the specific acts of violence are reported in Appendix A (Cronbach's alpha $=.80$ ).

\section{Exposure to Parental Violence}

This scale represents a summated index of violence perpetrated by each of the subjects' parents (or step-parents) toward each other (e.g. mother toward father, and father toward mother). The specific items comprising the scale are consistent with items used in the previously discussed child abuse scale. Items comprising the scale, as previously noted, range in severity from slapping, pushing, grabbing to more serious events including choking, beat up, and use of a knife or gun (Cronbach's alpha $=.94)$.

\section{Global Exposure to Violence}

To assess cumulative exposure to violence during childhood, we combined the scales measuring exposure to inter-parental violence and physical child abuse into an overall index assessing global exposure to violence (Cronbach's alpha $=.89$ ).

\section{Negative Life Events}

This 6-item summated scale gauges stressful events that occurred in respondents' childhood (prior to age 18). Across the disciplines of sociology and psychology, theorists 
suggest that exposure to stress or strain may motivate aggression, delinquency, or crime (Agnew, 1989; Agnew, 1992; Bandura, 1973). This scale contains items similar to measures used in prior research (Agnew and White, 1992; Hoffmann and Miller, 1998) that examined the relationship between strain and delinquency or crime, including parental separation and divorce, experiencing the death of a friend or parent, and excessive family moves (Cronbach's alpha $=.57$ ).

\section{Parental Alcohol-Related Problems}

Respondents were asked a series of questions about their parent's alcohol use, including whether or not their parents experienced alcohol-related problems. Examples include legal problems, school or work problems, and treatment for alcohol abuse. This measure reflects the number of problems (out of six) for each parent figure that the parolee reported their parents experiencing. (Cronbach's alpha $=.79$ for mother figures and .83 for father figures).

\section{Psychological Measures}

A limited range of psychological measures was included in the dātaset. Despite the limitations of the measures, it was decided to include them in the analysis in an effort to explore relationships that were of theoretical significance for the study.

IQ

Intelligence tests were performed on the respondents upon entering various correctional institutions. Typically, these tests were group administered with a short form IQ test. However, a small sub-set of offenders were subjected to longer, more in-depth testing if significant 
intellectual deficits were demonstrated upon admission. The data included here is based on the short from IQ test and unfortunately, includes a very high level of missing data.

Missing values were observed for $50 \%$ of the cases and in multivariate models, mean substitution was employed to address case attrition. ${ }^{5}$

\section{Psychological Problems}

This measure was created based on three items included in the parolee's pre-sentence investigation report. Specifically, each parolee was scored (yes or no) on whether they evidenced any psychotic, affective, or personality disorders. The measure for Psychological Problems represents a dummy variable indicating whether (coded " 1 " for yes) or not a subject was coded as "yes" on any of the three items."

\section{Parolee Self-Reported Deviance}

The data include several measures of deviance, including early delinquent onset, alcoholrelated problems, drug use, self-reported acts of violence, and intimate partner violence.

\footnotetext{
${ }^{5}$ Recognizing the possible problems associated with mean substitution for $50 \%$ of the cases, statistical models were also estimated models without the IQ variable. The substantive results remained the same.

${ }^{6}$ It is important to recognize that specific psychological disorders may have differential effects on criminal behavior. Therefore, in order to test the sensitivity of this measure, each component of the combined variable was stepped in separately into analyses to gauge whether particular psychological problems had effects on the dependent variable. There was no substantive difference between the components and the combined variable.
} 


\section{Delinquent Onset}

Early onset to delinquency is a strong and consistent correlate of adult offending (Loeber and Dishion, 1983; Wolfgang et al,, 1972). Moreover, according to recent theory and research, early delinquent participation is related to several criminal career dimensions including violence, enhanced offending frequency, versatility, persistence in crime, and offending chronicity (Moffitt, 1993; Patterson and Yoerger, 1993; Blumstein et al., 1986; Piquero et al., 1999; Tolan, 1987). Respondents are classified as having early onset status in the present analysis if they report engaging in one of four criminal acts (e.g.theft, burglary, assault, or robbery) prior to the age of 13 .

While our selection of early onset prior to age 13 appears arbitrary, past research has utilized similar criteria (Tolan, 1987). Using this age cut-off is desirable because it clearly precedes and is not confounded with adolescent-limited delinquency (see Moffitt, 1993). It is assumed that this age criteria better reflects early onset to delinquency when using self-reported information given that official intervention to adolescent delinquency typically follows already established juvenile offending patterns (Paterson and Yoerger, 1993). ${ }^{7}$

\section{Alcohol-Related Problems}

This measure reflects the number of alcohol-related problems experienced by the respondent (out of twenty-one problems) over their lifetime. Examples of problems include job

\footnotetext{
${ }^{7}$ It should be noted that we examined various relationships using other age criteria to index early onset to delinquency, and the results were not substantively different. We employed the current age cut-off, delinquency prior to age 13, to be consistent with Moffitt's conception of life-course persistent offending.
} 
or school difficulties, drinking while ill, and neglecting responsibilities because of drinking binges. A complete list of alcohol-related problems included in the scale is reported in Appendix A (Cronbach's alpha $=.83)$.

\section{Illicit Drug Use}

A measure for illicit drug use was included which indexes the number of different illicit drugs (e.g. heroin, barbiturates, cocaine, marijuana, LSD, and PCP) that the respondent used on a regular basis. Regular illicit drug use was defined as weekly use of a substance for at least a month (Cronbach's alpha $=.67$ ).

\section{Self-Reported Violence}

Respondents reported whether or not they had ever committed a number of violent criminal acts. The measure reflects the respondent's participation in a number of different types of violent crimes including assault, kidnapping, robbery, armed robbery, and rape.

\section{Intimate Partīer Violence}

Similar to measures for childhood exposure to violence, the measure for intimate partner violence (derived from a revised version of the CTS) reflects the number of violent acts perpetrated by the parolee toward his intimate partner in the year prior to his current incarceration. Unlike the CTS measures for early childhood violence, the male parolees were asked to report on nine (rather than twelve) specific violent acts including items ranging in severity from slapped, hit with something to even more serious acts such as used knife or gun, choked, and forced sex. The specific acts comprising the scale are reported in Appendix A. As 
noted earlier, the respondents were asked about intimate partner violence across two points in time, the year prior to their incarceration, and the three months prior to the interview.

\section{Methodological Considerations Regarding Intimate Partner Violence}

There are two methodological considerations with regard to using the CTS. The first concerns the use of couple reports, and the second concerns changes in sample composition based on whether or not a particular parolee was in a relationship during the valid CTS period (and therefore had an opportunity to perpetrate intimate partner violence).

With regard to the first issue, we acknowledge that couple reports (e.g. combining both partners' reports) may represent a more valid indicator of partner violence (Szinovacz, 1983). However, limitations with the data preclude using them for the current analysis. While the data do include CTS scores reported by the parolees' intimate partners, for the year prior to prison, partner reports were only available for 29 of the 111 male parolees. The parolees' intimate partners also contributed information for the three-month window after their partner's release from prison. Again, because some parolees' partners did not complete the CTS, utilizing couple reports would further diminish an already relatively small sample (from 107 to 88 ). Further, analysis of reporting patterns shows a great deal of disagreement - with no clear pattern of bias, especially for cases in which there is violence (there is substantial agreement where neither couple reports acts of violence). ${ }^{8}$ Consequently, in the current study we rely on male parolee reports of partner violence, which past research demonstrates are acceptable under certain research conditions (see Moffitt et al., 1997).

\footnotetext{
${ }^{-8}$ An analysis of parolee/partner responses to various CTS responses is presented in Appendix B
} 
With regard to the second issue, parolees were only given the CTS if they were in a relationship in one of the opportunity windows (one year prior to incarceration, and three months prior to the post-release interview). Therefore, it becomes necessary to check whether parolees who are in a relationship differ across measures such as demographics and criminal risk. To investigate whether male parolees who were in a relationship prior to prison $(\mathrm{N}=111)$ differed from those who were not $(\mathrm{N}=69)$, we compared the groups on demographic and criminal history information as well as their drug/alcohol use patterns and level of exposure to violence in childhood. Most of the comparisons revealed no differences between the groups although two differences were observed. Male parolees in a relationship were significantly older and had more prior incarcerations. ${ }^{9}$

A similar analysis was conducted comparing parolees who were in a relationship in the three months prior to the interview $(\mathrm{N}=107)$ with those who were not $(\mathrm{N}=73)$. The groups differed only in regard to race, with non-white parolees being more likely to be in a relationship.

\section{Demographic Information}

Information on demographic characteristics is included for age (measured in years) and race (codes as $1=$ white, $0=$ non-white). Additionally, there are several measures that tap into socioeconomic status. Welfare status refers to whether the respondent received welfare in the three months prior to the interview (yes $=1$ ). Job Status is an ordinal measure and reflects the occupational prestige (from menial labor to white collar positions) of the respondent's job when

9 There were no-differences between groups when a prevalence measure of prior incarceration was used. Thus, the groups differed only in the frequency of their prior incarcerations. 
they are employed. Higher scores on this measure reflect occupations with greater levels of prestige. The variable "education" measures the level of education obtained on a seven points scale ranging from less than $8^{\text {th }}$ grade" (coded as 1) to "completed a college degree" (coded as 7). Finally, the variable income is the respondent's estimate of their weekly take-home pay. For some analyses, a composite SES variable was created by factor analyzing these four variables. Information on the sample characteristics and various measures are reported in Table 1.1. 
Table 3.1 - Descriptive Statistics

\begin{tabular}{|c|c|c|c|c|}
\hline Variable & $\mathbf{N}$ & Mean & Sd & Range \\
\hline Early Life Events & & & & \\
\hline Child Abuse & 179 & 6.75 & 4.42 & $0-25$ \\
\hline Observe Parents Violence & 174 & 5.12 & 5.97 & $0-23$ \\
\hline Global Violence & 173 & 11.72 & 8.53 & $0-43$ \\
\hline Negative Live Events & 180 & 1.57 & 1.45 & $0-5$ \\
\hline Father Figure's Alcohol Problems & 179 & 1.15 & 1.56 & $0-6$ \\
\hline Mother Figure's Alcohol Problems & 179 & 0.36 & 0.93 & $0-6$ \\
\hline Psychological Measures & & & & \\
\hline Psychological Problems & 180 & 0.01 & 0.26 & $0-1$ \\
\hline IQ & 90 & 96.86 & 12.48 & $64-122$ \\
\hline \multicolumn{5}{|l|}{ Self-Reported Deviance } \\
\hline Lifetime Alcohol Problems & 180 & 5.85 & 5.84 & $0-21$ \\
\hline Number of Drugs Used Regularly & 180 & 1.84 & 1.58 & $0-6$ \\
\hline Early Delinquent Onset $(<13)$ & 180 & 0.53 & 0.50 & $0-1$ \\
\hline Self Report Violence & 180 & 1.37 & 1.05 & $0-5$ \\
\hline $\begin{array}{l}\text { Intimate Partner Violence (year prior to } \\
\text { prison) }\end{array}$ & 111 & 1.05 & 1.33 & $0-6$ \\
\hline $\begin{array}{l}\text { Intimate Partner Violence ( } 3 \text { months prior } \\
\text { to interview) }\end{array}$ & 107 & 2.62 & 3.05 & $0-13$ \\
\hline
\end{tabular}




\section{Table 3.1 Continued - Descriptive Statistics}

\begin{tabular}{lcccc}
$\begin{array}{l}\text { Demographics } \\
\text { Age }\end{array}$ & 180 & 32.41 & 7.80 & $20-72$ \\
Race (white =1) & 180 & 0.32 & 0.47 & $0-1$ \\
Education & 180 & 4.43 & 1.47 & $1-7$ \\
Welfare Status (1 = received welfare) & 180 & 0.36 & 0.48 & $0-1$ \\
Job Status & 177 & 3.06 & 1.40 & $1-8$ \\
Income & 178 & 64.44 & 119.74 & $0-1000$ \\
Socioeconomic Status & 180 & 0.00 & 1.00 & $-1.2-4.3$ \\
\hline
\end{tabular}

\section{ANALYSIS PLANS}

The results of various analyses are reported in the following three chapters. In Chapter 4, we examine the predictors of early onset delinquency. Specifically, the analyses are designed to address the following research questions:

(a) Is early exposure to violence related to life-course persistent offending status?

i. Is exposure to inter-parental violence related to early onset offending?

ii. Is exposure to physical child abuse related to early onset offending?

(b) Is exposure to parental alcohol abuse related to early onset offending?

(c) Are negative life events related to early onset offending?

(d) Is IQ related to early onset offending?

Examining these research questions involves examining the characteristics associated with delinquent onset status (e.g. early or late-onset delinquents)- As noted earlier, our definition of life-course-persistent offending is based on whether or not individuals engaged in criminal activities prior to age 13 . The first step in the analysis examines baseline (mean level) 
relationships between the discrete offending groups (early and late onset) and various childhood measures. Next, the research questions outlined above are addressed using a multivariate (logistic regression) analysis.

The analyses presented in Chapter 5 addresses the relationship between discrete offender groups, childhood exposure to violence and various forms of deviance. Again, the presentation moves from baseline (bivariate) relationships to multivariate analyses. The following research questions are addressed:

(a) Are LCP offenders more likely to engage in deviance as adults?

i. Are LCP offenders more likely to abuse alcohol or drugs?

ii. Are LCP offenders more likely to report more violent crimes?

(b) Are LCP offenders more likely to engage in intimate partner violence?

For multivariate analyses, the nature of the intimate partner violence measures (e.g., limited range of response, positive skew) suggests using an alternative to ordinary least squares (OLS) regression. OLS regression operates under the assumption that the dependent variable is continuous and normally distributed (Blalock, 1979). In practice, using OLS regression with a limited and skewed dependent variable results in problems with unequal error variance, and ultimately to inflated standard errors, which decreases the likelihood of rejecting the null hypothesis.

Fortunately, there are a number of statistical techniques designed to analyze "count variables," (e.g., number of arrests, number of problems) that, by their nature, tend to be limited and skewed (Long, 1997).--Poisson regression is the most basic statistical model for analyzing count variables, and most other techniques are based on the Poisson model. Poisson regression 
is a maximum likelihood estimation technique where the probability of a "count" is determined by a Poisson distribution, where the mean of the distribution is a function of the independent variables (Long, 1997). A defining characteristic of this model is that the conditional mean of the outcome is equal to the conditional variance. This circumstance is often not true in practice. Typically, the conditional mean exceeds the conditional variance-a condition referred to as "overdispersion."

Practically speaking, using the Poisson model when overdispersion is present will result in spuriously large $z$ values, because the standard errors will be biased downward (Long, 1997). Preliminary models indicated that overdispersion was not present. Nevertheless, all multivariate models were replicated using OLS regression (which results in more conservative hypothesis tests). These tests indicated that the Poisson models did not exaggerate (inflate) the effects of independent variables and the substantive conclusions remained the same.

Chapter 6 brings evidence from this data to bear on an unsettled issue in the family violence literature. That is, whether being abused a child as opposed to observing inter-parental conflict and violence has similar or distinct effects on the likelihood of intimate partner violence in adulthood. Data is presented in this chapter that examines the effects of both (a) observing parental violence during childhood, and (b) being abused by parents in childhood on the likelihood of perpetrating intimate partner violence during adulthood. Results in this chapter shed light on the following questions:

(a) Is childhood exposure to violence related to adult deviance?

i. Are LCP offenders more likely to abuse alcohol or drugs?

ii. Are LCP offenders more likely to report more violent crimes? 
(c) Is childhood exposure to violence related to adult intimate partner violence?

i. Are the effects of early exposure to violence similar for both child abuse and observing parental violence? 


\section{CHAPTER 4: EXAMINING DISCRETE OFFENDING GROUPS}

\section{INTRODUCTION}

This chapter is the departure point for the analysis of discrete offending groups. The chapter begins with a brief discussion of the prevalence of LCP offenders within the present sample. Next, offenders meeting the criteria for LCP status are compared with the remainder of the sample on a number of theoretically relevant variables. These bivariate comparisons allow for a comparison of whether any of the variables tapping either early life events or time stable characteristics can distinguish the two types of offenders. The chapter concludes with a multivariate analysis (logistic regression) predicting early onset status.

\section{PREVALENCE OF EARLY ONSET OFFENDERS IN THE SAMPLE}

Moffitt (1993) suggests that life-course-persistent offenders comprise approximately $5 \%$ of any birth cohort. Less is known, however, about the prevalence of LCP offenders within an offender population. Information from birth cohort studies suggest that high rate chronic offenders represent upwards of $20 \%$ of an offending population, using "police contacts" as the offending criteria (Wolfgang, Sellin, and Figlio, 1972). Samples of incarcerated offenders, or offenders recently released from prison, would be expected to have much higher proportions of LCP offenders, given the greater concentration of serious offenders within correctional institutions.

When our criteria for discrete offending groups (i.e., any of four crimes committed prior to age 13) are employed, $53 \%$ of the sample is classified as "early onset" delinquents. Because 
we recognize that choosing this age cut-off is somewhat arbitrary (but see, Tolan, 1987), a measure using age 14 was also developed. As expected, this made the early onset group more inclusive, with $62 \%$ of the sample labeled as LCP. We used this alternative to test the sensitivity of our models in subsequent analyses. Unless otherwise noted, the definitional change made no substantive difference in outcomes.

\section{RELATIONSHIPS BETWEEN EARLY ONSET STATUS AND EARLY LIFE EVENTS}

Moffitt (1993) theorizes that the cause of early onset (or "life-course-persistent") offending is a potent interaction between neuropsychological deficits (present at birth) and socialization (e.g. weak parenting skills). While a full test of this process is beyond the scope of this chapter, her theory (see also, Patterson, 1993) suggests that socialization variables and social adversity play a salient role in early delinquent onset. Further, she argues that individual differences in temperament should distinguish early onset offenders from late onset offenders.

We examine here the bivariate relationships between early onset status and variables tapping both individual differences (IQ, psychological problems) as well as social adversity (negative life events, parental alcohol problems). We are particularly interested in the relationship between early onset status and childhood exposure to violence (e.g., being abused, observing parental violence). There is a substantial literature linking child abuse and neglect with juvenile delinquency and violence (Rivera and Widom, 1990; Smith and Thornberry, 1995; Thomberry, 1994; Widom, 1996). To date, however, researchers have tended not to integrate violence within the family with the lifecourse perspective of delinquency. Table-4.1 provides a summary of the results for these bivariate analyses. The results are discussed in detail below. 
Table 4.1 - Bivariate Relationships Between Early Onset Status and Theoretically Relevant Measures

\begin{tabular}{llll}
\hline Variable & \multicolumn{1}{c}{ Mean: } & Mean: & t \\
& $\begin{array}{l}\text { Life-course } \\
\text { Persistent }\end{array}$ & Late Onset & \\
\hline IQ & 98.04 & 95.49 & 1.95 \\
Race (1 = white) & 0.36 & 0.28 & 1.09 \\
Negative Life Events & 1.83 & 1.26 & $2.67^{* *}$ \\
Psychological Problems & 0.01 & 0.01 & 0.53 \\
Mother Alcohol Problems & 0.59 & 0.10 & $3.76^{* *}$ \\
Father Alcohol Problems & 1.20 & 1.08 & 0.50 \\
Child Abuse & 7.89 & 5.45 & $3.86^{* *}$ \\
Parent Violence & 6.64 & 3.41 & $3.75^{* *}$ \\
Global Violence & 14.26 & 8.90 & $4.39^{* *}$ \\
\hline
\end{tabular}

The relationship between IQ and delinquency is well documented (Hirschi and Hindelang, 1979; Moffitt , 1991, 1993). Moffitt (1993) argues that IQ is a adequate measure of general neurological health, and therefore important in understanding the life-course persistent offending trajectory. Prior research suggests that IQ may indeed distinguish life-coürepersistent offenders from other offenders more so than it does offenders from non-offenders 
(Maahs, 2001). Inspection of table 4.1, however, reveals that IQ does not distinguish early onset offenders from the remainder of the sample in this data. ${ }^{10}$

Moffitt (1993) also notes that as adults, LCP offenders exhibit personality characteristics consistent with known mental disorders, including psychopathy. While we have no direct measure of psychopathy, we do test whether psychological problems (including personality disorders) are related to early onset offending. Table 4.1 again reveals no support for this hypothesis.

Theoretically, this suggests that the two groups of offenders do not differ in important theoretical constructs. However, both measures have serious limitations (e.g. missing data for IQ, and limited categories for psychological problems). Given these constraints, nutf findings are not surprising.

The results concerning the effects of adversity and family violence are more supportive of our expectations. Moffitt (1993) places a great deal of importance on the role of social adversity and parenting skills. Specifically, she posits that LCP pathway children are expected to have a difficult temperament and be raised by parents who are ill equipped (either due to social adversity or poor parenting skills) to handle them. Prior research has confirmed that socialization variables, such as parenting skills and social adversity measures, such as family disruption and poverty (Loeber and Dishon, 1983; Patterson and Yoerger, 1993; Sampson and Laub, 1993) are related to delinquency in general and specifically, early onset delinquency. We

\footnotetext{
${ }^{10}$ We should note here that Moffitt (1993) emphasizes the interactive nature of IQ. That is, she believes that neuropsychological deficits (tapped by IQ) interact with socialization and adversity variables. We test this proposition with multivariate models.
} 
test here several measures that are consistent with adversity and parenting, including negative life events, parental alcohol abuse, and parental violence.

The measure "negative life events" taps into noxious experiences (e.g. parental separation, household moves, etc.) experienced by the subjects prior to age 18 . Prior research has linked similar measures with delinquency (Hoffmann and Miller, 1998; Paternoster and Mazerolle, 1994), although not with early onset delinquency. The relationship between negative life events and early onset status is illustrated in Figure 4.1. Consistent with our expectations, individuals who experience more negative life events during childhood are more likely to evidence an early onset of delinquency.

\section{Figure 4.1 - The Relationship Between Negative Life Events and LCP Status}
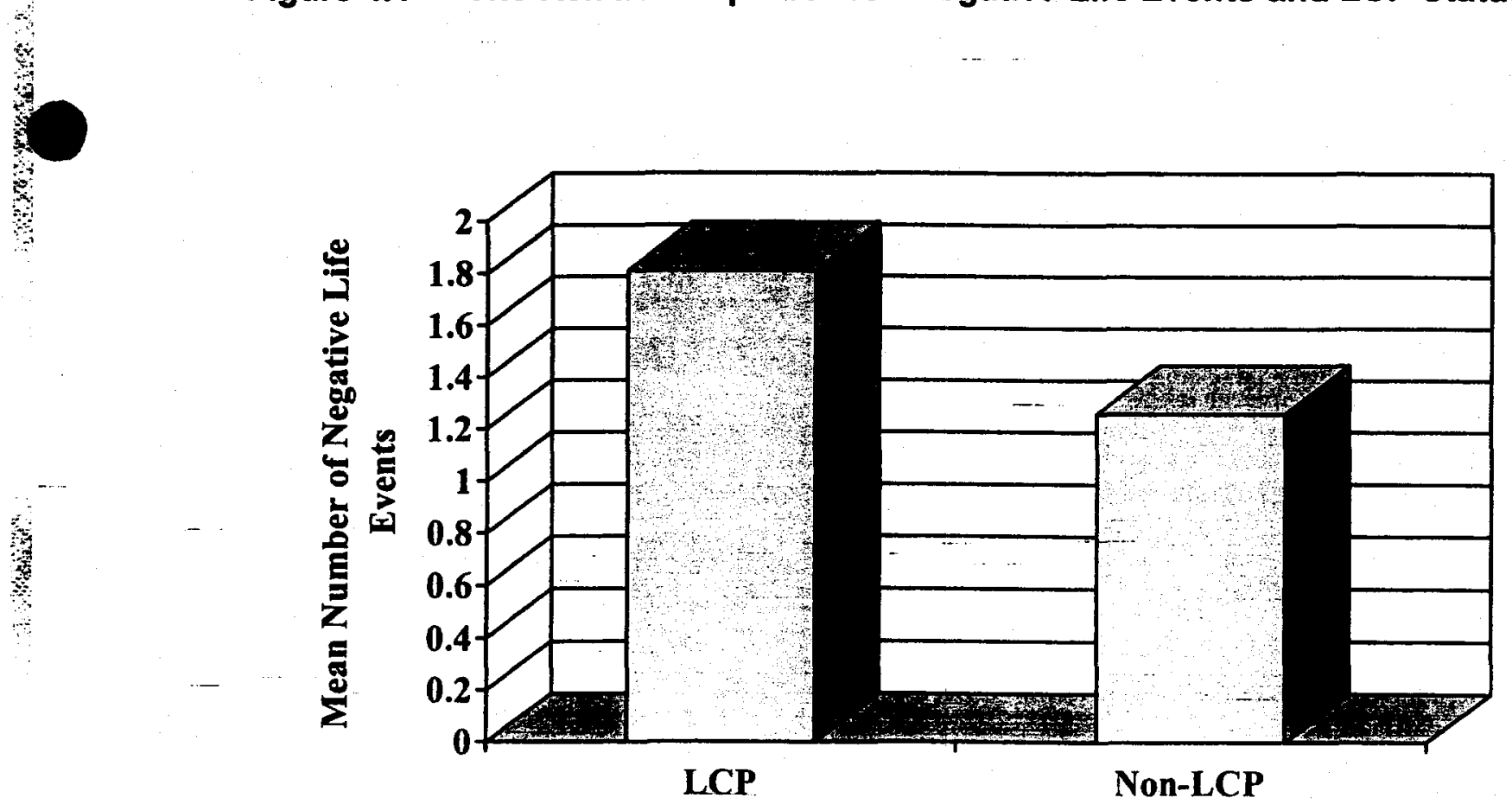
Parental alcohol abuse may contribute to early onset status in at least two ways. First, parents who abuse alcohol are expected to have a greater likelihood of abusing and neglecting their children. Additionally, alcohol abuse may disrupt effective parenting practices, including the consistent monitoring and consistent discipline that prevent the early onset of delinquency (Laub and Sampson, 1988). The relationship between parental alcohol problems and early onset status is displayed in Figure 4.2. While early onset offenders are more likely to have mothers with alcohol problems, the relationship does not hold true for fathers. This pattern suggests that alcohol abuse may interfere with childrearing practices (or a mother-child bond), a finding which is consistent with research linking maternal self esteem and depression to childhood antisocial

behavior and delinquency (Cohen, Velez, Brook, and Smith, 1989; Dubow, and Luster 1990; Leadbeater, and Bishop, 1994). 
Figure 4.2 - The Relationship Between Mother and Father Figure's Alcohol Related Problems and Early Onset Status

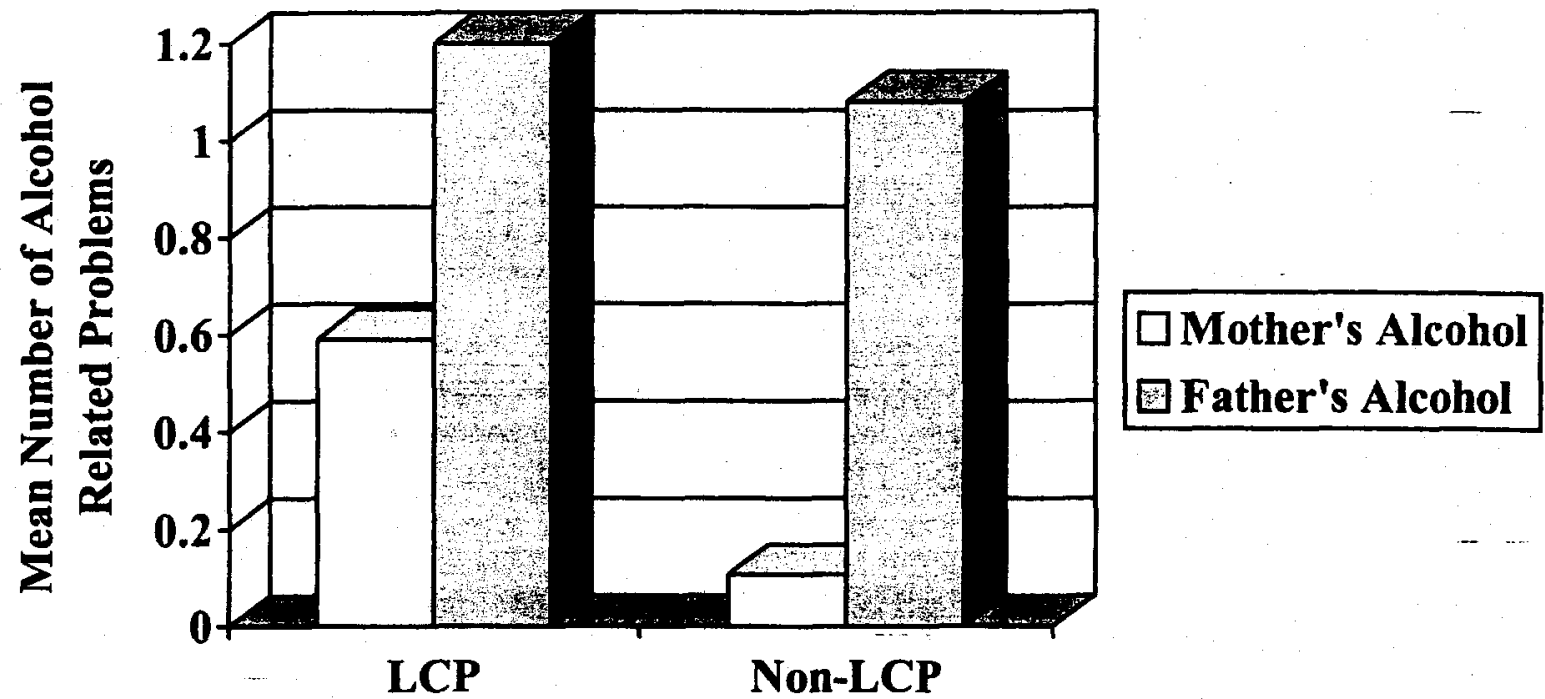

The relationship between family violence during childhood and early onset delinquency is illustrated graphically in Figure 4.3. Again, these relationships conform to theoretical expectations. As noted earlier, both of these measures are derived from a version of the conflict tactic scale, and tap into behaviors ranging from slapping to the use of weapons. Because these measures are variety indexes, and do not gauge frequencies of any type of event, higher scores logically reffect more serious forms of violence.

In this comparison, early onset offenders were more likely to have experienced child abuse $($ mean $=7.9)$ than other offenders $($ mean $=5.5)$. A similar relationship appears with regard to observing inter-parental violence. Specifically, early onset offenders (mean $=6.64$ ) observed nearly twice the level of parental violence as other offenders in the sample (mean = $3.51)$. 
In sum, these baseline comparisons yielded mixed results-supporting our expectations with regard to the role of social adversity, but not for individual traits. Next, we turn to the multivariate analysis to further explore these relationships.

Figure 4.3 - The Relationship Between Family Violence and LCP Status

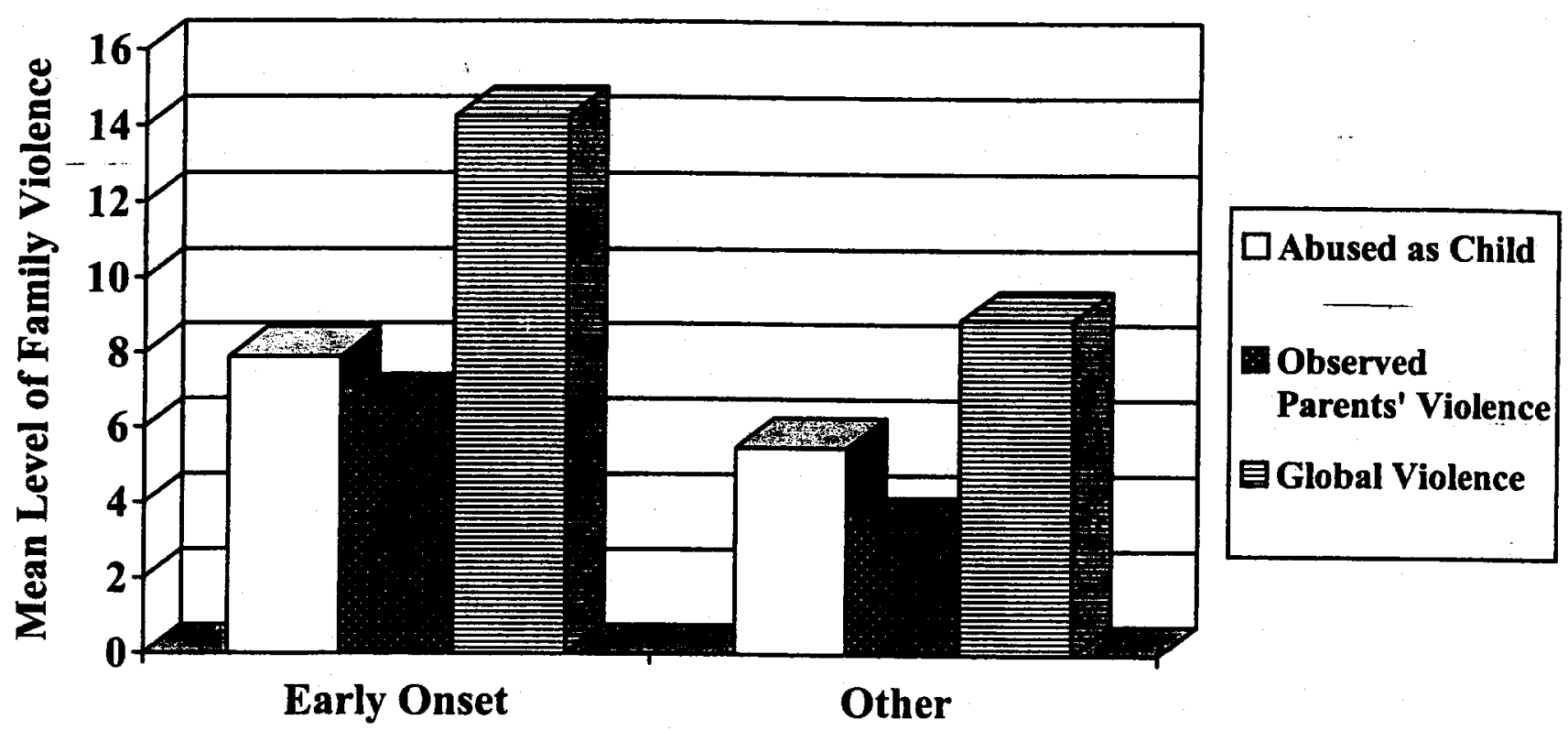




\section{CHARACTERISTICS ASSOCIATED WITH LIFE-COURSE PERSISTENCE: MULTIVARIATE ANALYSIS}

Moving from bivariate to multivariate analysis, Table 3.2 displays the results of a series of logistic regression equation predicting onset status. " Each of the family violence measures are stepped in separately to examine the differential effects of child abuse and observing parental violence. The baseline model (first on left) confirms the results of the bivariate analyses. That is, both negative life events and maternal alcohol problems (but not fathers) distinguish the early onset group from the rest of the sample. Further, neither IQ nor psychological problems are significantly related to onset status. ${ }^{12}$

The remaining three columns indicate that each measure of family violence maintains significance in multivariate analyses. That is, individuals who experienced higher levels of child abuse and those who observed their parents using violence and abusing each other were more likely to have an early onset to delinquency. Inspection of Table 3.2 also suggests family violence is related to maternal alcohol abuse. Specifically, the effect of maternal alcohol problems on onset status is diminished when child abuse is included in the equation, and loses significance when parental violence is included. This suggests that the effects of maternal

\footnotetext{
"Theoretically, the formation of IQ or psychological problems, and exposure to negative life events and family violence precede the onset of delinquency. However, the retrospective and general nature of the data does not allow us to rule out reciprocal or reverse causality through time ordering. We acknowledge therefore, that some of the relationships may be reciprocal (e.g. early onset delinquency may foster child abuse or parental violence).

${ }^{12}$ As noted earlier, Moffitt (1993) suggests an interaction between neuropsychological predisposition and social adversity. We tested this specific hypothesis by creating a multiplicative interaction term (combining IQ and each of our adversity measures). These analyses revealed no significant interaction.
} 
alcohol use on early onset status may be partially mediated by violent experiences within the family.

Table 4.2 - Logistic Regression Predicting LCP Status

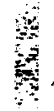

\begin{tabular}{lcccc}
\hline Variable & & & & \\
\hline IQ & .035 & .034 & .036 & .035 \\
Race & $1.057^{* * *}$ & $1.058^{* * *}$ & $1.070^{*}$ & $1.092^{* *}$ \\
Negative Life Events & $.328^{* *}$ & .177 & $.311^{*}$ & .222 \\
Psychological Problems & -.284 & -.350 & -.163 & -.232 \\
Mother Alcohol & $.631^{* *}$ & $.577^{* *}$ & .390 & .386 \\
Father Alcohol & .010 & -.015 & -.149 & -.151 \\
Child Abuse (global) & & & & - \\
Parent Violence (global) & -- & $.033^{* *}$ & -- & - \\
Global Violence & -- & -- & $.030^{* *}$ & -- \\
\hline
\end{tabular}

${ }^{*} \mathrm{p}<.10 ;{ }^{* *} \mathrm{p}<.05 ; \quad * * * \mathrm{p}<.01 ; \quad$ Unstandardized Coefficients Reported

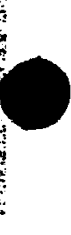




\section{CHAPTER SUMMARY}

It is worth noting, again, that the preceding analyses attempted to distinguish two groups of offenders from each other. Further, both types of offenders had criminal records or committed crimes serious enough to warrant prison time. The point here is that our analyses (and construction of early onset status) does not involve a comparison between minor offenders and chronic offenders. Rather, we constructed these groups based on onset-age in an effort to understand the genesis of life-course-persistent behavior.

Our findings (with the exception of IQ) largely conform to our expectations, and help shed light upon the role of family violence (i.e., experiencing child abuse and observing interparental violence) and maternal alcohol abuse. Specifically, we found that both types of family adversity play a role in the early onset of delinquency. Additionally, the results suggest that experiencing child abuse and observing inter-parental violence may partially mediate the effect of maternal alcohol abuse on early onset to delinquency.

The findings are consistent with previous research examining child abuse and neglect, and illustrate the importance of early intervention efforts to help prevent juvenile delinquency. Specifically, programs designed to prevent child abuse, parental violence and parentatalcohol abuse are warranted. There is evidence that such programs do prevent serious juvenile delinquency - the type of delinquency most likely to be perpetrated by LCP offenders (for a general review, see Currie, 1998). In the following chapter, we examine adult outcomes for the discrete offending groups, including alcohol abuse, illicit drug use, and intimate partner violence. In short, we examine the types of outcomes early intervention might help prevent. 


\section{CHAPTER 5: DISCRETE OFFENDER GROUPS, NEGATIVE LIFE OUTCOMES, AND INTIMATE PARTNER VIOLENCE}

\section{INTRODUCTION}

In this chapter, we examine the relationships between discrete offender groups consistent with Moffitt's developmental theory and the probability of perpetrating intimate partner violence. Like the last chapter, the analysis begins with a series of bivariate comparisons. Rather than focus on early life events, however, the analysis focuses on the adult outcomes associated with life-course-persistent status.

\section{LIFE OUTCOMES FOR LIFE-COURSE PERSISTENT OFFENDERS}

The hallmark of the life-course-persistent offender (Moffitt, 1993) or "early starter" (Patterson, 1993) is stability in antisocial behavior through adolescence and into adulthood. Further, theorists suggest that LCP type offenders exhibit more generality in their antisocial behavior. As Moffitt (1993:679) states, "Across the life course, these individuals exhibit changing manifestations of antisocial behavior: biting and hitting at age 4, shoplifting and truancy at age 10 , selling drugs and stealing cars at age 16 , robbery and rape at age 22 , and fraud and child abuse at age $30 . . . "$

An obvious implication of this proposition is that members of our LCP group should be more enmeshed in antisocial behavior than other individuals in the sample. Available research reveals early delinquent participation to be positively correlated with offending frequency and 
versatility (Tolan and Lorion, 1988; Tolan, 1987; Piquero et al., 1999) as well as chronic offending (Loeber and LeBlanc, 1990; Wolfgang et al., 1972).

An additional implication of discrete offending groups is that the causal mechanisms leading to crime differs across different types of offenders. For example, the logic of theories predicting dual routes to delinquency (Moffitt, 1993a; Patterson, 1993; Simons et al., 1994 ) suggests that only early starters (or LCP's) should evidence high levels of family adversity, or low levels of cognitive functioning.

Research testing this proposition has yielded results both favorable and unfavorable to taxonomic theorists. For example, using data from Farrington's classic study on delinquent development in the United Kingdom, Nagin et al. (1995) probabilistically assigned individuals based on their adult offending patterns, to one of four groups (high level chronics, low level chronics, adolescent limiteds, and non-offenders). Subsequent analyses revealed that the three offender groups could not be distinguished on most measures of risk (troublesomeness, truancy, general deviance). However, adolescent limiteds had greater job stability and were more attached to their spouse atage 32 then either of the chronic groups.

The analyses reported here earlier (Chapter 4 ) also yielded mixed results. While the LCP group evidenced more family violence and greater levels of maternal alcohol abuse, the groups could not be distinguished based on IQ, psychological problems, or paternal alcohol abuse.

A final issue regarding the applicability of discrete offending groups to adult life outcomes, including intimate partner violence, is the concept of "cumulative continuity" (Moffitt, 1993; Patterson, 1993; Sampson and Laub, 1993). While Moffitt (1993) argues that the LCP groups gets off on the wrong foot very early in life, she does not believe that parenting and 
neuropsychological deficits can fully account for the stability in antisocial behavior exhibited by this group. To fully explain this stability, she argues that initial antisocial behavior can ensnare some individuals in the consequences of their behavior. That is, early antisocial behavior affects the probability of future antisocial behavior because it affects factors in a person's environment (e.g., forming a drug habit, alcohol abuse, school failure) that negatively impact antisocial behavior.

Given prior research and extant theory, we believe that LCP status will be an important predictor of various negative life outcomes, including alcohol abuse, illicit drug use, and violent behavior in adulthood. Further, we expect that LCP status will remain an important predictor of intimate partner violence, when other risk factors are controlled in multivariate models. Finally, given Moffitt's (and other life-course theorists') contention that cumulative continuity partially explains the stability of antisocial behavior in the LCP group, we expect that the effects of illicit drug use and alcohol abuse on intimate partner violence will be attenuated when discrete offender groups are considered in a multivariate model. Each of these hypotheses is explored below.

\section{BASELINE RELATIONSHIPS BETWEEN DISCRETE OFFENDING GROUPS AND ADULT OUTCOMES}

As noted above, we expect to find mean level differences across our discrete groups of offenders for a variety of adult outcomes, including drug and alcohol abuse, as well as violence generally, and intimate partner violence specifically. The results of our mean level comparisons are illustrated in Figures 5.1 through 5.4. 
Figure 5.1 reveals the association between onset status and alcohol abuse. Consistent with theoretical expectations, LCP offenders exhibit a higher mean level $($ mean $=6.9)$ of alcoholrelated problems than the remainder of offenders (mean $=4.7)$ in the sample. This mean level difference is statistically significant $(\tau=2.53, p<.05)$. A similar pattern emerges with respect to illicit drug use. Figure 5.2 reveals a similar pattern with respect to the regular use of illicit drugs. Specifically, while LCP offenders report regularly using an average of 2:2 illicit drugs, the remainder of offenders report using an average of 1.5 . While this difference is certainly not dramatic, it does attain statistical significance $(t=2.95, p<.01)$. Thus far, the analysis reveals that LCP offenders have higher rates of alcohol abuse and illicit drug use. These relationships are important along two lines. First they demonstrate that LCP status has implications for adult substance use. Second, these relationships leave open the possibility of cumulative continuityLCP status is related to substance use, which in turn may affect other forms of antisocial behavior. We address this issue through multivariate procedures reported below. For now, however, we turn to the relationship between LCP status and violence.

Moffitt (1993) suggests that LCP offenders are more likely to engage in violent antisocial behavior than other types of offenders. Indeed, she suggests that violent behavior may be the only way to distinguish adolescent-limited offenders from LCP offenders during adolescence. We therefore expect LCP offenders to perpetrate more violence (both general and intimate personal viōence) than other offenders. Figures 5.3 illustrates that this research hypothesis holds with regard to a variety index of self-reported violence (e.g., robbery, rape, etc.). Specifically, LCP offenders report committing an average of 1.5 different violent acts, while the 
other parolees in the sample committed an average of 1.2. While this difference is not substantively striking, it does conform to expectations and is statistically significant $(t=2.34$; $\mathrm{p}<.05)$

Of course, we are most interested, for the purpose in this report, in the relationship between intimate partner violence and discrete offending groups. Figure 5.4 illustrates the relationship between LCP status and intimate partner violence for parolees who were in relationships in either the year prior to incarceration $(\mathrm{N}=111)$ or in the three months prior to being interviewed $(\mathrm{N}=107)$. In the year prior to incarceration, LCP offenders perpetrated twice the level of intimate partner violence $($ mean $=1.4$ ) as non-LCP parolees $($ mean $=0.6)$. This mean level difference is statistically significant $(t=3.10, p<.01)$. While the mean difference is not as great for the second time period, the same pattern holds. Specifically, in the three months prior to the interview, LCP offenders report significantly more intimate partner violence (mean $=$ 1.75) than other parolees $($ mean $=1.0)(\mathrm{t}=2.95, \mathrm{p}<.05)$.

Overall then, our bivariate analyses reveal no surprises. LCP offenders engage in more antisocial behavior over their lifecourse than other parolees in the sample. This holds true for both substance use and abuse, as well as violence. We turn now to multivariate analyses to assess whether LCP status remains important when other factors are controlled, and to explore certain aspects of cumulative continuity. 
Figure 5.1 - The Relationship Between LCP Status and Lifetime Alcohol Problems $(t=2.53, p<.05)$

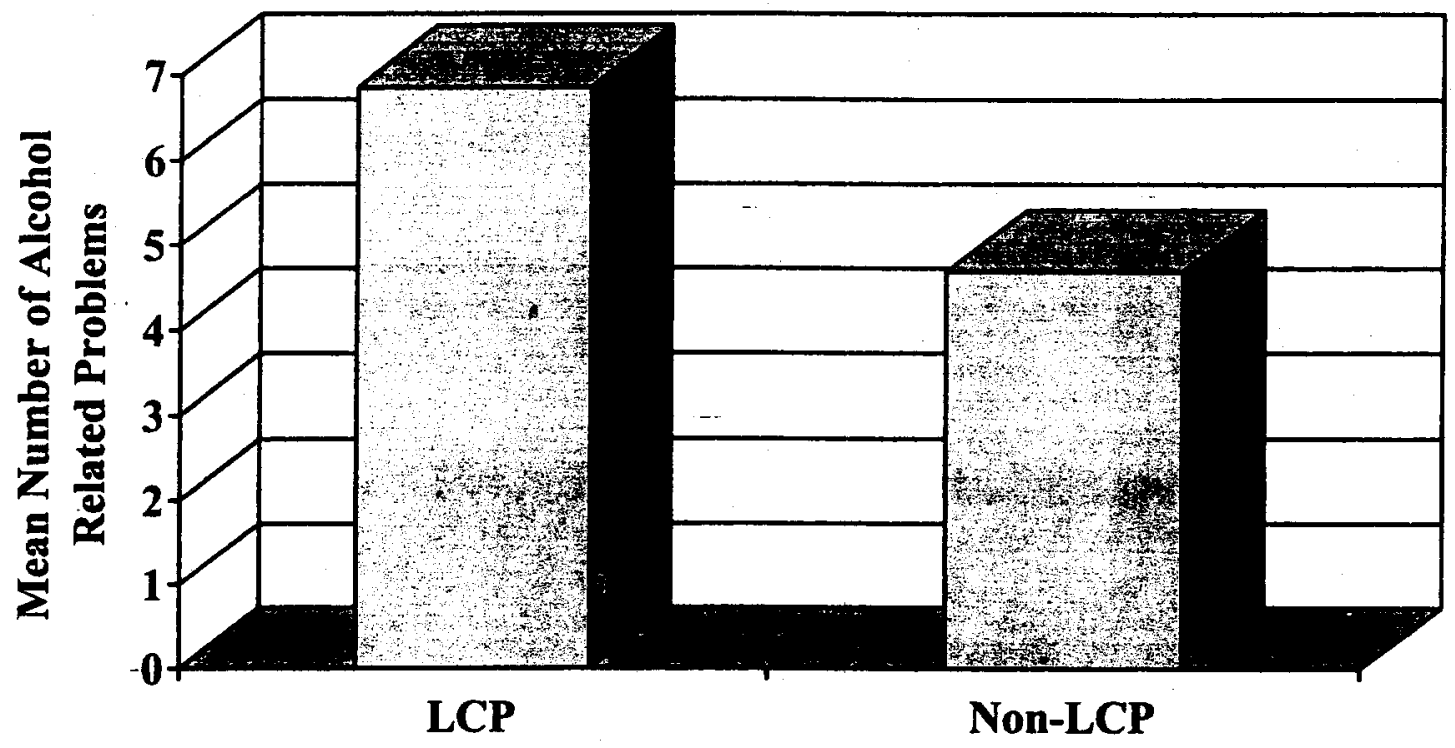

Figure 5.2 - The Relationship Between LCP Status and Illicit Drug Use $(t=2.95 ; p<.01)$

3

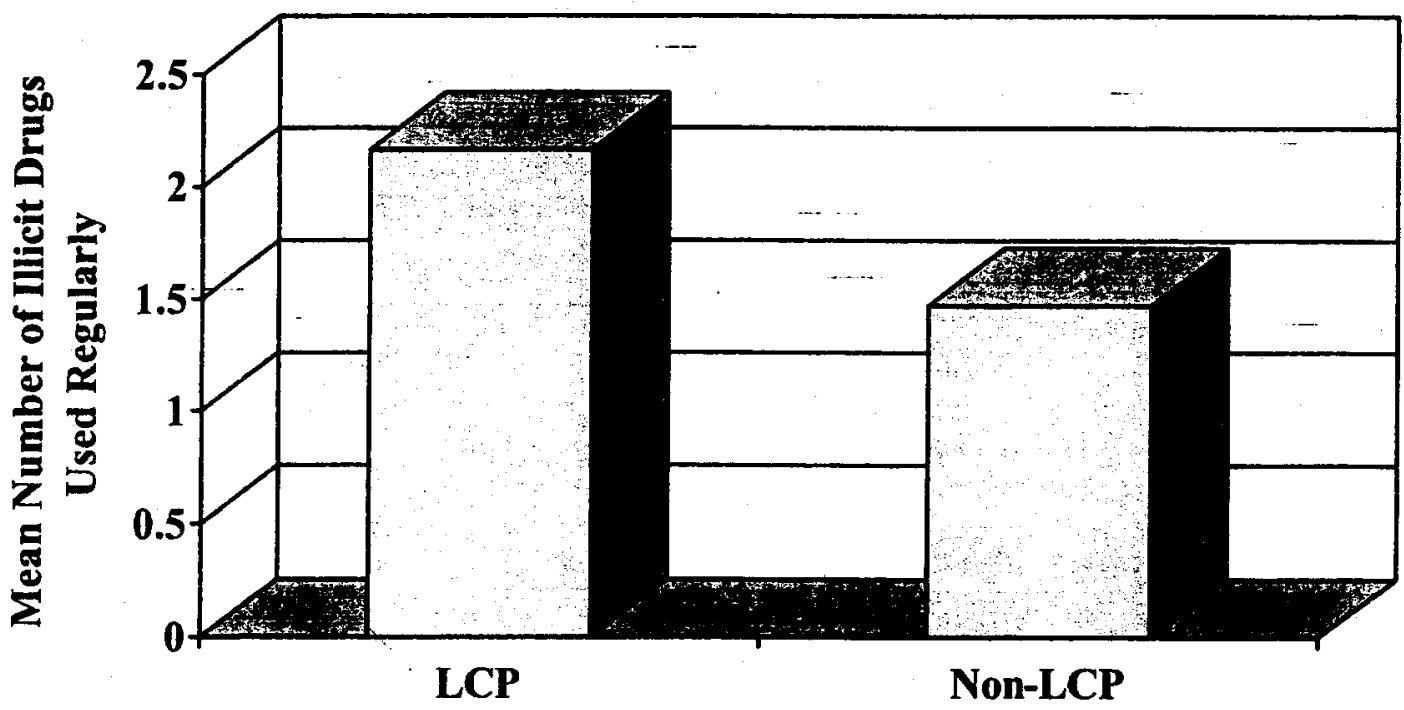


Figure 5.3 - The Relationship Between LCP Status and Self-Reported Violence $(t=2.34 ; p<.02)$

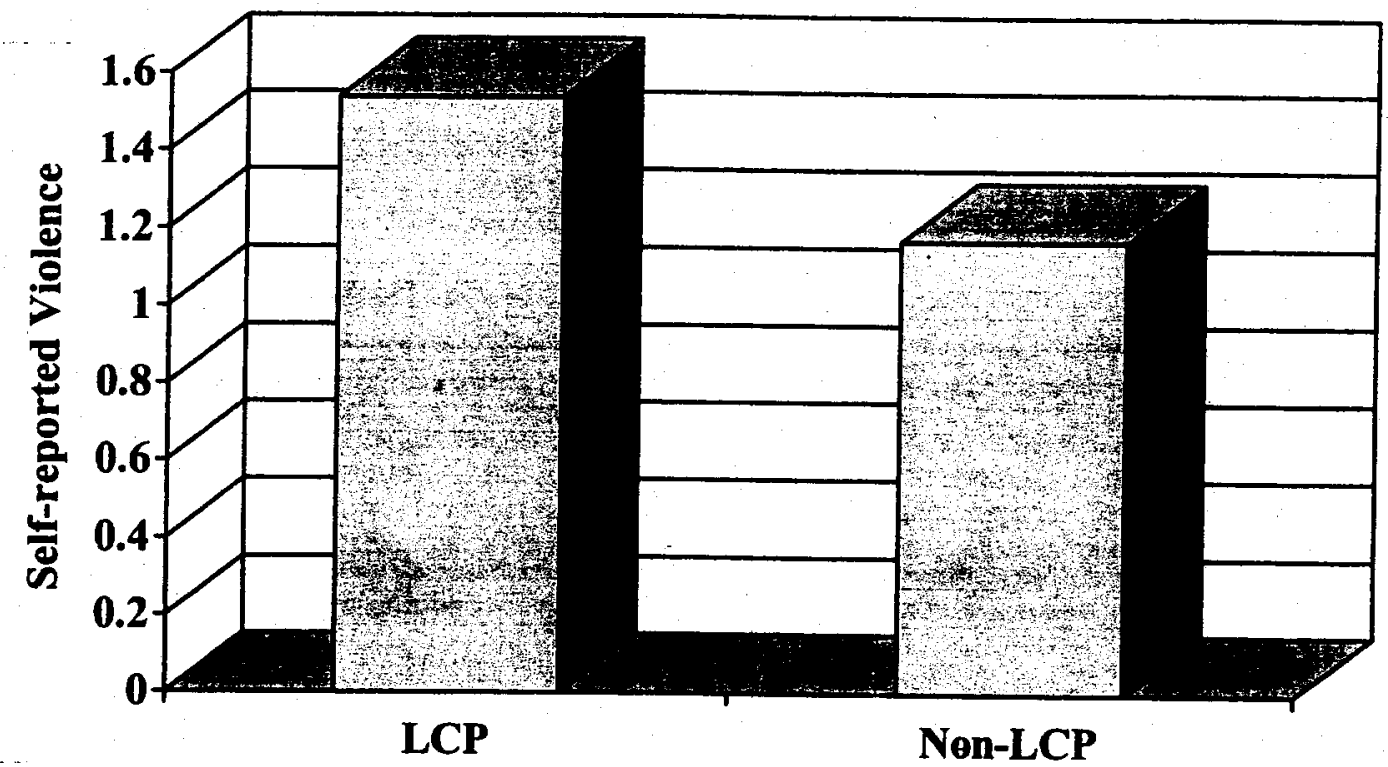

Figure 5.4 - The Relationship Between LCP Status and Intimate Partner Violence
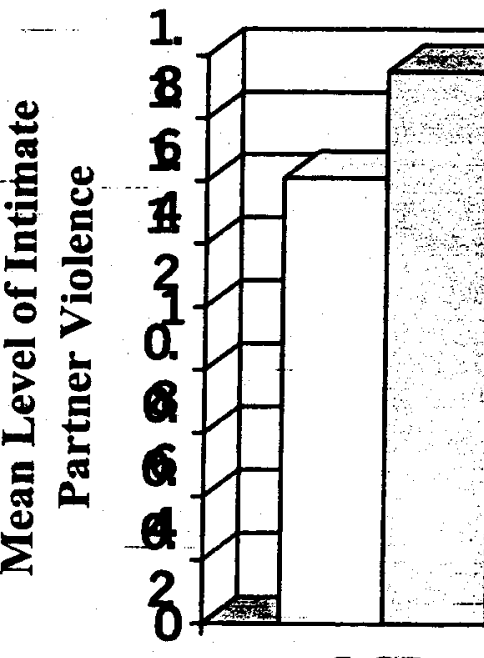

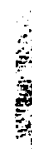

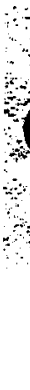

Non-LCP

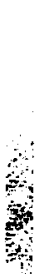

LCP

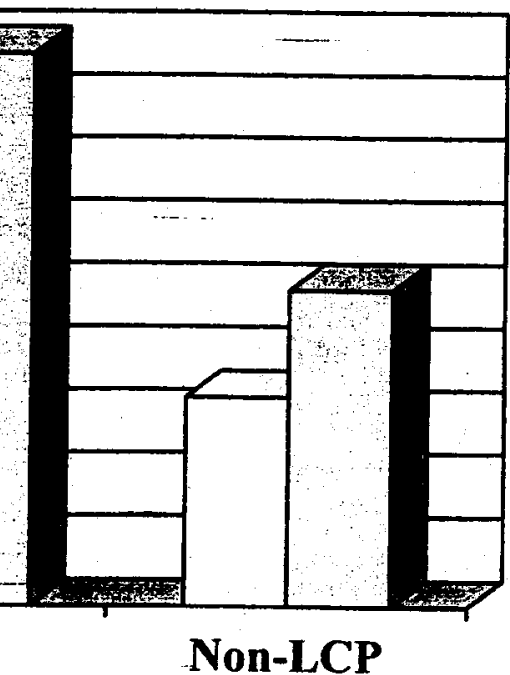

Non-LCP $\square$ Year Prior to Prison $(\mathrm{t}=3.10, \mathrm{p}<.01)$

$\square$ Three Months Prior to Interview $(t=2.19, p=.03)$ 


\section{MULTIVARIATE ANALYSIS OF INTIMATE PARTNER VIOLENCE}

To further investigate the relationship between early onset status and intimate partner violence, we present below the results from a series of Poisson regression equations. Again, Pöisson regression is preferred over OLS regression, given the limited and skewed values in the dependent variables (i.e., intimate partner violence at both time points). ${ }^{13}$ Table 5.1 displays unstandardized coefficients for three separate Poisson regression models predicting intimate partner violence in the year prior to the parolees' prison term. In the base model (first column under model 1), only demographic variables (age, race, job status, and education) and substance use (alcohol abuse, illicit drug use) are entered as covariates. ${ }^{14}$

Consistent with our bivariate analyses, both alcohol abuse and illicit drug use significantly increase the probability of intimate partner violence, net of controls for demographic characteristics. Again, both variables are consistent with past research and theory - parolees who have more alcohol-related problems, and those who use more illicit drugs, perpetrate higher levels of intimate partner violence. None of the remaining variables (age, race, education, job status) are related to partner violence.

_ In the column labeled model 2, LCP status is entered into the base model. Again in this model, none of the demographic variables significantly predict intimate partner violence. LCP status, however, does emerge as a significant predictor of partner violence. Further, the effects

\footnotetext{
${ }^{13}$ To test the sensitivity of this method, we also estimated OLS regression equations. The substantive results remained the same.

${ }^{14}$ All socioeconomic status information was derived from the interview data, and therefore, some of the measures cannot be applied retrospectively to the year prior to prison time period (e.g. welfare status). In lieu of the composite SES measure, we therefore include measures that are relatively time-stable.
} 
of both alcohol abuse and illicit drug use on intimate partner violence are slightly attenuated, and illicit drug use is no longer statistically significant. This suggests that the relationship between substance use/abuse and intimate partner violence stems, in part, from their mutual relationship to LCP status. However, alcohol abuse does remain a significant predictor of intimate partner violence, suggesting a possible role for cumulative continuity. That is, LCP appears to foster alcohol abuse (as evidenced by the bivariate analyses, and by the slight attenuation in the multivariate model), but alcohol abuse has an independent effect on intimate partner violence.

Table 5.2 replicates the previous regression models, changing the dependent variable to the measure gauging intimate partner violence reported during the three months (post release) prior to the interview. Also, a composite measure of socioeconomic status is used in lieu of job status and education. Starting again with model 1, inspection of Table 5.2 reveals similar results to the previous analysis. Specifically, none of the demographic information predicts intimate partner violence. Conversely, both alcohol abuse and illicit drug use are significant predictors. Again, the direction of the relationship is consistent with expectations-increases in alcohol problems and illicit drug use is associated with higher levels of intimate partner violence.

In the second model, LCP status is entered into the equation, and the results are strikingly similar to the model predicting intimate partner violence during the year prior to incarceration. Specifically, LCP offenders perpetrate significantly more intimate partner violence than other parolees. Further, inclusion of LCP status in the model slightly diminishes the effect of both substance use measures on the dependent variable-in this case, reducing the effect of alcohol abuse to insignificance. Thus, the multivariate models predicting intimate partner violence for two different windows of time tell a similar story. That is, LCP offending is clearly associated 
with intimate partner violence, and tends to attenuate the effects of other variables (e.g. alcohol abuse and illicit drug use).

In the third column of Table 5.2, reported under model 3, we explore what happens when the dependent variable from the first set of models (IPV in the year prior to incarceration) is entered as a covariate. Inspection of this model reveals, as one might expect, that there is substantial stability in intimate partner violence across the two time periods. The results illustrate the continuity in intimate partner violence among parolees in this sample, as previous partner violence appears to have the strongest effect on more recent partner violence, net of other influences. Moreover, given that past intimate partner violence is statistically controlled in the model, the results can be interpreted as assessing changes in the outcome measure, net of controls. Additionally, despite the obvious heterogeneity in the model, which is captured in the prior partner violence measure, other influences remain significantly related to more recent partner violence.

In addition to the models displayed in Tables 5.1 and 5.2, we analyzed the intimate partner violence data over both time periods for interaction effects. As noted earlier, the logic of a "dual route" theory suggests that the causes of antisocial behavior (in this case, intimate partner violence) might differ between LCP and non-LCP offenders. For example, one might suspect that childhood variables (e.g. family violence, maternal alcohol abuse) might be more salient for LCP offenders, while substance abuse might be more important for non-LCP offenders. To test this assertion, we ran separate models for each discrete offender group. The substantive pattern 
of relationships between predictor variables and intimate partner violence was the same across groups. $^{15}$

\section{CHAPTER SUMMARY}

This chapter examined relationships between discrete offending groups (LCP vs nonLCP) consistent with Moffitt's developmental theory across a range of negative life outcomes, including intimate partner violence. Initial bivariate analyses illustrated differences between offender groups on a range of outcomes. Specifically, LCP offenders exhibited higher levels of alcohol abuse, illicit drug use, and general violence. Moreover, LCP offenders engaged in higher levels of intimate partner violence, a pattern witnessed across two time periods.. Taken together with the results of Chapter 4, these bivariate analyses suggest that discrete offender groups (i.e., LCP), indexed by delinquent onset age, are related to important outcomes across the lifecourse in a theoretically expected manner.

Results from our multivariate analyses do not cast doubt on this assertion. LCP status was a robust and significant predictor of intimate partner violence across measures of intimate partner violence from two time periods, independent of other variables (e.g., drug use, alcohol abuse). Further, LCP status diminished (but did not eliminate) the effect of alcohol abuse and drug use on intimate partner violence. We expected that LCP status would attenuate these effects because a hallmark of the LCP pathway is stable antisocial behavior across the lifecourse, but also varied antisocial outcomes. The fact that in each model, one of these variables remained significant suggests that cumulative continuity might also be at work.

${ }^{15}$ To be sure, these null findings might stem from the small sample sizes (less than 50 in some cāses) that resulted from separating the discrete offender groups. 


\section{Table 5.1 - Poisson Regression Models Predicting Intimate Partner Violence In the Year Prior to Incarceration ${ }^{1}$}

\begin{tabular}{lll}
\hline Variable & Model 1 & Model 2 \\
\hline Age & -0.01 & -0.01 \\
Race & -0.19 & -0.05 \\
Education & 0.01 & -0.07 \\
Job Status & 0.001 & 0.001 \\
Lifetime Alcohol Problems & $0.04^{* *}$ & $0.03^{*}$ \\
Illicit Drug Use & $0.14^{*}$ & 0.10 \\
LCP Status (LCP =1) & \multicolumn{1}{c}{$0.68^{* *}$} \\
Model $\chi^{2}$ & $18.9^{* *}$ & $29.8^{* *}$ \\
\hline
\end{tabular}

${ }^{1}$ Unstandardized Coefficients Reported

${ }^{*} \mathrm{p}<.05 * * \mathrm{p}<.01 \quad$ (One-tailed test). 
Table 5.2 - Poisson Regression Models Predicting Intimate Partner Violence within Three Months of Interview'

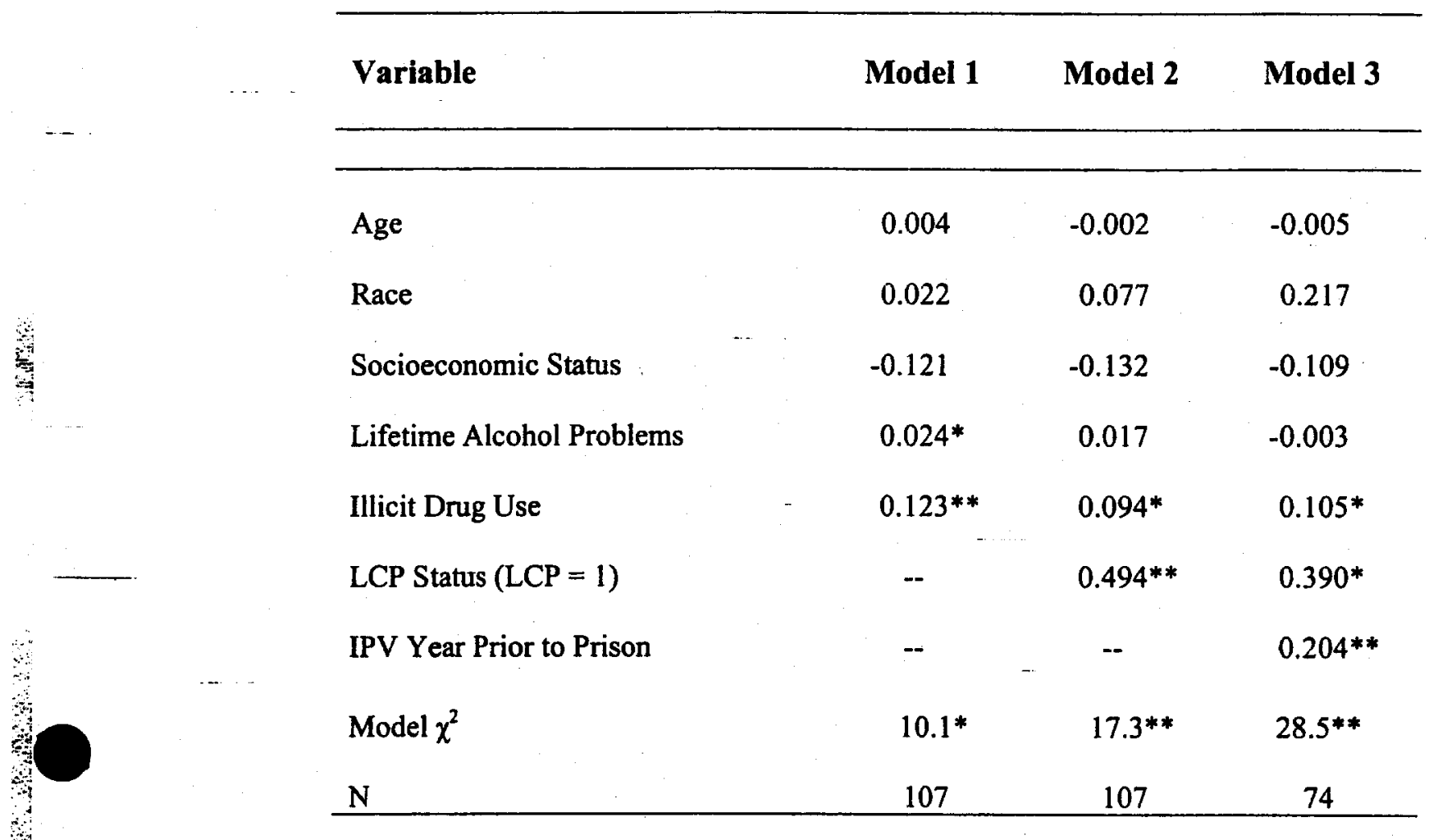

${ }^{1}$ Unstandardized Coefficients Reported

${ }^{*} \mathrm{p}<.05{ }^{* *} \mathrm{p}<.01$

谭

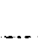




\section{CHAPTER 6: CHILDHOOD EXPOSURE TO VIOLENCE: COMPARING THE EFFECTS OF CHILD ABUSE AND OBSERVING PARENTAL VIOLENCE ON NEGATIVE LIFE OUTCOMES}

\section{INTRODUCTION}

There are reasons to believe that exposure to physical child abuse and observing interparental violence in childhood might be differentially related to intimate partner violence later in adulthood. To be sure, there are many pathways and precursors to intimate partner violence, but one of the consistent risk factors is having witnessed inter-parental violence while growing up (Hotaling and Sugarman, 1986). Individuals exposed to inter-parental violence in childhood are expected to recall many of the contexts and patterns that were involved in their parents' violent incidents. Such experiences set up expectations for behavioral scripts between partners. Within this context, males are likely to embrace physical means of social interaction and dispute resolution within their marital relationships. Consistent with this belief, research reveals that batterers are more likely to have poor communication and social skills (Holtzworth-Munroe and Stuart, 1994) and educational attainment (Hotaling and Sugarman, 1986). Moreover, further research examining the direct and indirect linkages between witnessing inter-parental violence and partner violence finds that ineffective conflict resolution skills and marital distress mediate the relationship between exposure to inter-parental violence and subsequent partner violence perpetration. Using data from the Second National Family Violence Survey (Gelles and Straus,

1989), Choice and colleagues (1995) find support for the mediating effects of ineffective conflict 
resolution skills and partner violence. However, their results also reveal direct relationships between exposure to parental violence and subsequent partner violence by males. In sum, there is good evidence that exposure to inter-parental violence in childhood is one of the strongest and

- most consistent predictors of male perpetrated intimate partner violence. Additionally, there are reasons to believe that some of these effects are direct and some are more indirect (see also Downs et al., 1996).

Research suggests that exposure to physical child abuse increases the probability of violent behavior (Thomberry, 1994; Rivera and Widom, 1990; Hotaling et al., 1989; Wolfe et al., 1998). However, there are reasons to suspect that the effects of childhood exposure to physical abuse are less strongly related to intimate partner violence than observing inter-parental violence. First, past exposure to physical child abuse has not been identified as a consistent risk factor for intimate partner violence (Hotaling and Sugarman, 1986; Kalmuss, 1984). Second, past research linking physical child abuse with partner violence has not consistently isolated the independent effects of exposure to physical child abuse and observing inter-parental violence (Dutton, 1988; Kalmuss, 1984). As a result, many of these relationships may be over-stated or confounded because the criminogenic effects of observing inter-parental violence were not isolated and controlled. Finally, despite research revealing that exposure to physical child maltreatment leads to physical conflict in dating relationships (Wolfe et al., 1998), such relationships are arguably not as strong when directly compared to the independent effects of observing inter-parental violence. In sum, in light of past research, we expect exposure to inter-parental violence during childhood to be more strongly related to male perpetrated intimate partner violence in adulthood than is exposure to physical child abuse. 
In this chapter, we examine relationships between early exposure to violence and a range of negative outcomes. Our hypothesis is that exposure to violence in the family is associated with a range of problematic outcomes including substance abuse, delinquency, and violence. Moreover, we examine whether there is a consistent "dose response" between exposure to violence in childhood and problems in adulthood. In other words, we explore whether greater exposure to violence during childhood is associated with more problems later in adulthood.

A second hypothesis to be tested concerns whether exposure to certain types of violence in childhood are more strongly related to intimate partner violence. Past research has not consistently examined whether exposure to multiple types of violence in childhood is differentially related to partner violence. Our analysis examines the independent effects of childhood exposure to physical child abuse and observing inter-parental violence on intimate partner violence.

\section{EFFECTS OF EXPOSURE TO VIOLENCE ON NEGATIVE LIFE OUTCOMES}

The relationship between different levels of exposure to cumulative levels of violence in childhood and various negative outcomes are displayed in Figures 6.1 through 6.4. The relationship between exposure to violence in the family and early delinquent onset is presented in Figure 6.1 and reveals a finding consistent with theoretical expectations: increasing levels of exposure to violence in the family during childhood is associated with more early delinquent participation, which functions as an index for LCP status. Put another way, earlier exposure to violence in the family increases one's chance of becoming an LCP offender. 
Exposure to violence in childhood is also expected to lead to problems with alcohol and substance abuse later in life (Duncan et al. 1996). Results displayed in Figures 6.2 and 6.3 allow us to examine this issue further. The findings are largely consistent with our expectations. For example, high levels of exposure to childhood violence are associated with a greater number of problems with alcohol use (mean=8.5) for respondents with medium (mean=4.8) or low levels (mean= 4.4) of exposure. Additionally, the results reveal support for rejecting the null hypothesis of there being no mean level differences in alcohol use problems across groups. ( $F=$ $4.9, \mathrm{p}<.01) .^{16}$

The results comparing mean level differences in drug abuse across respondents differentiated by varying levels of exposure to violence during childhood are displayed in Figure 6.3. The results are substantively consistent with theoretical expectations. Exposure to high levels of violence during childhood is associated with higher levels of illicit drug use within our sample. For example, the mean number of illicit drugs used regularly was 2.4 for parolees with high exposure to violence in childhood compared to a mean of 1.4 drugs used regularly for parolees with low levels of exposure to violence during childhood. While these differences are not dramatic (and not statistically different in this comparison, $\mathrm{F}=2.5, \mathrm{p}>.05$ ), the general pattern of results is consistent with expectations that greater exposure to violence in the family during childhood is associated with more illicit drug use problems in adulthood. ${ }^{17}$

\footnotetext{
${ }^{16}$ Post hoc pairwise comparisons indicate that individuals exposed to high levels of childhood violence experience significantly more alcohol related problems as adults than those with low levels of exposure to violence during childhood.

${ }^{17}$ Failing to find a statistical difference in this comparison is perhaps not surprising given the relatively small size of the sample as well as its "high risk" composition.
} 
Exposure to violence during childhood is also expected to be strongly associated with violent behavior in adulthood (Thornberry, 1994; Rivera and Widow, 1990). The results in Figures 6.4 and 6.5 highlight the nature of this relationship for self-reported violent crime and intimate partner violence. The findings are largely consistent with our expectations. For example, the results in Figure 6.4 reveal significant differences in mean levels of self reported violent crime for parolees with varying levels of exposure to violence during childhood $(\mathrm{F}=6.4$, $\mathrm{p}<.01)$. Parolees with high levels of exposure to violence during childhood reported over twice as many violent crimes as parolees with low levels of exposure.

64

This document is a research report submitted to the U.S. Department of Justice.

This report has not been published by the Department. Opinions or points of view

expressed are those of the authors) and do not necessarily reflect the official

- position or policies of the U.S. Department of Justice. 
Figure 6.1 - The Relationship Between Childhood Exposure to Violence and Early Onset of Delinquency

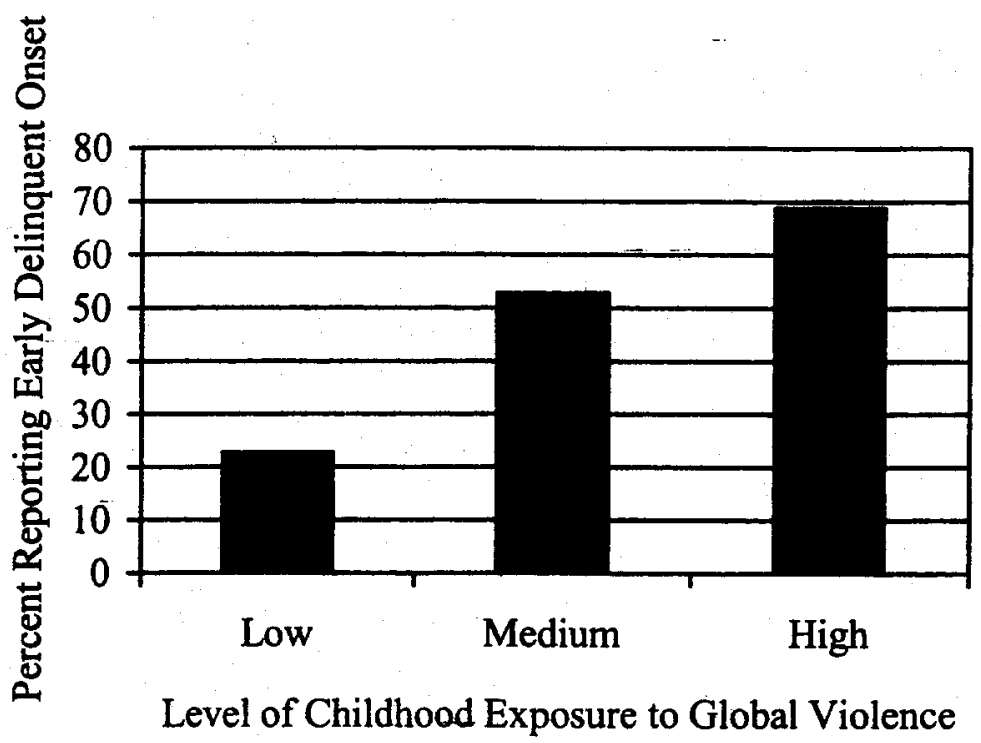

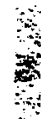

3

3

Level of Childhood Exposure to Global Violence 
Figure 6.2 - The Relationship Between Childhood Exposure to Violence and Lifetime Alcohol Problems

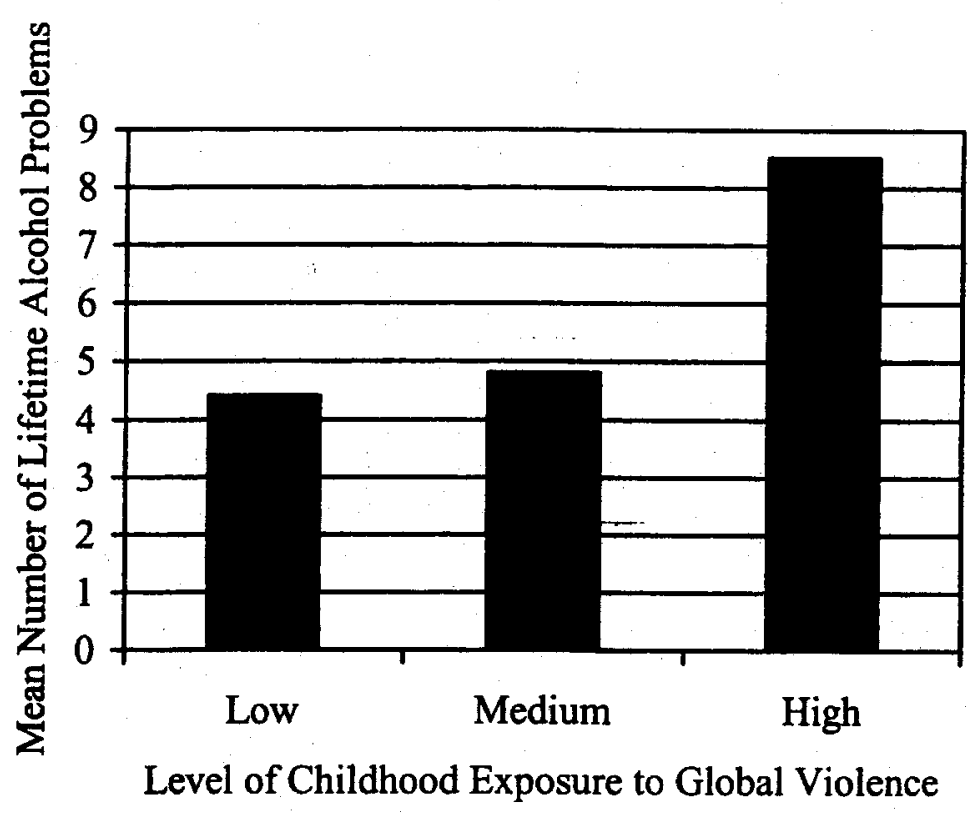

3

Level of Childhood Exposure to Global Violence

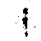


Figure 6.3 - The Relationship Between Childhood Exposure to Violence and Number of Drugs Used Regularly
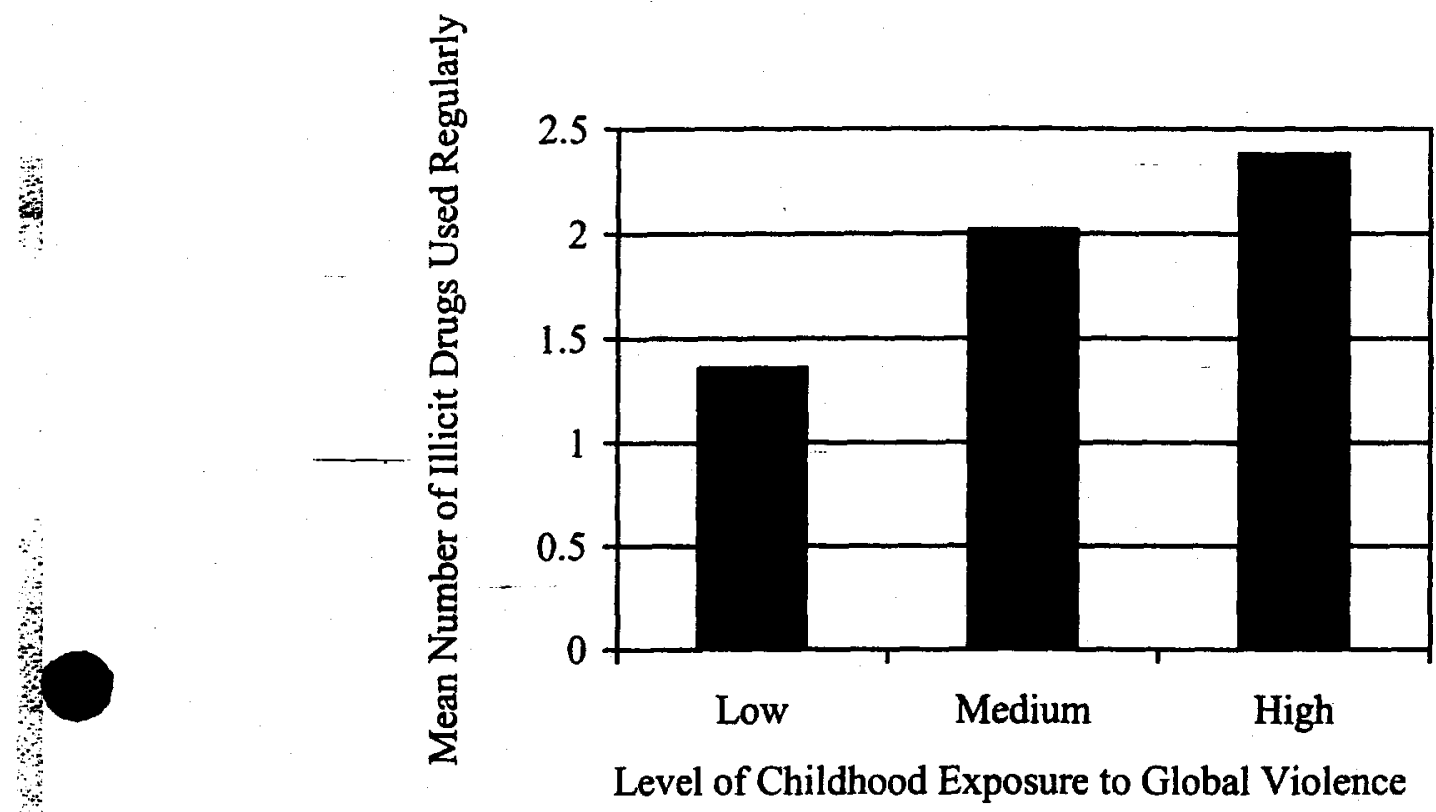

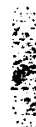

67 
Figure 6.4 - The Relationship Between Childhood Exposure to Violence and Self-Reported Violent Crime

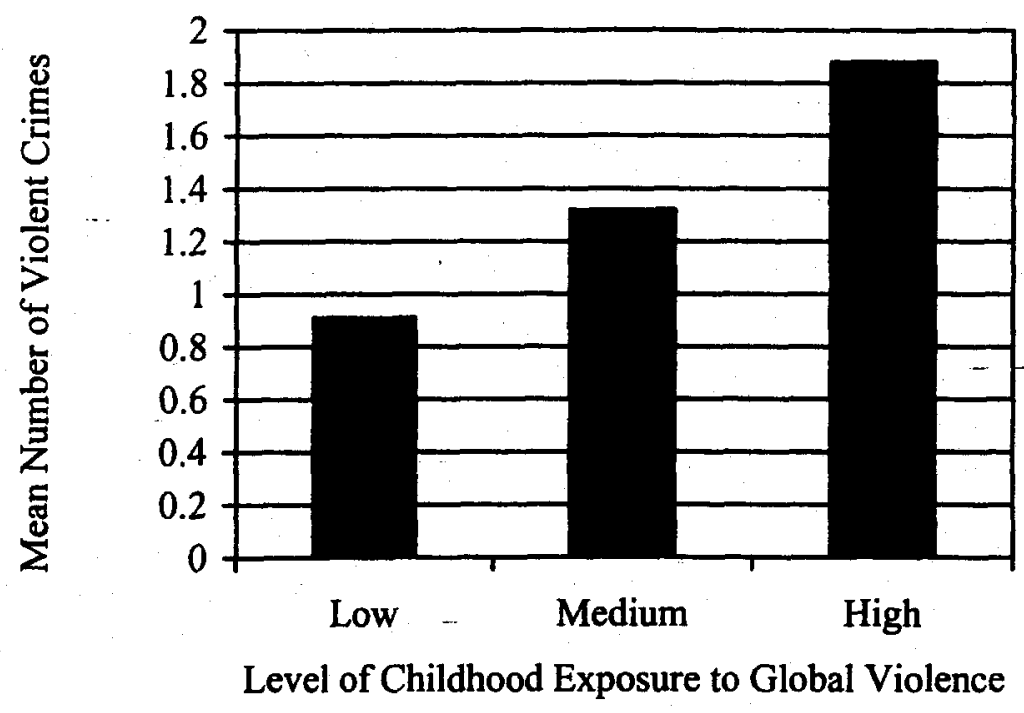

$(\mathrm{F}=6.42, \mathrm{p}<.01)$

Level of Childhood Exposure to Global Violence

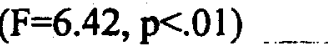

$\sqrt{n}$ 
Finally, the relationship between childhood exposure to violence in the family and intimate partner violence perpetration in adulthood (in the year prior to current incarceration) is reported in Figure 6.5. The results reveal a general pattern that is consistent with our expectations that higher childhood exposure to violence is associated with higher mean levels of partner violence within the sample. However, despite the fact parolees with high levels of childhood exposure to violence report over twice the level of partner violence as parolees with low levels of childhood exposure to violence, the relationship is not statistically significant $(F=$ $2.3, p>.05)$.

Thus far our results reveal a consistent pattern. Greater exposure to violence in the family during childhood is associated with a range of negative outcomes. While some mean level differences between groups were not large enough to reject the null hypothesis, all of the relationships were substantive and in the theoretically expected direction. It is important to acknowledge that these comparisons did not control for extraneous influences. Additionally, these comparisons did not examine whether childhood exposure to different types of violence differentially affects certain outcomes, such as partner violence. We now examine whether childhood exposure to physical child abuse and observing parental violence have independent influences on intimate partner violence through a series of multivariate models. 
Figure 6.5 - The Relationship Between Childhood Exposure to Violence and Intimate Partner Violence

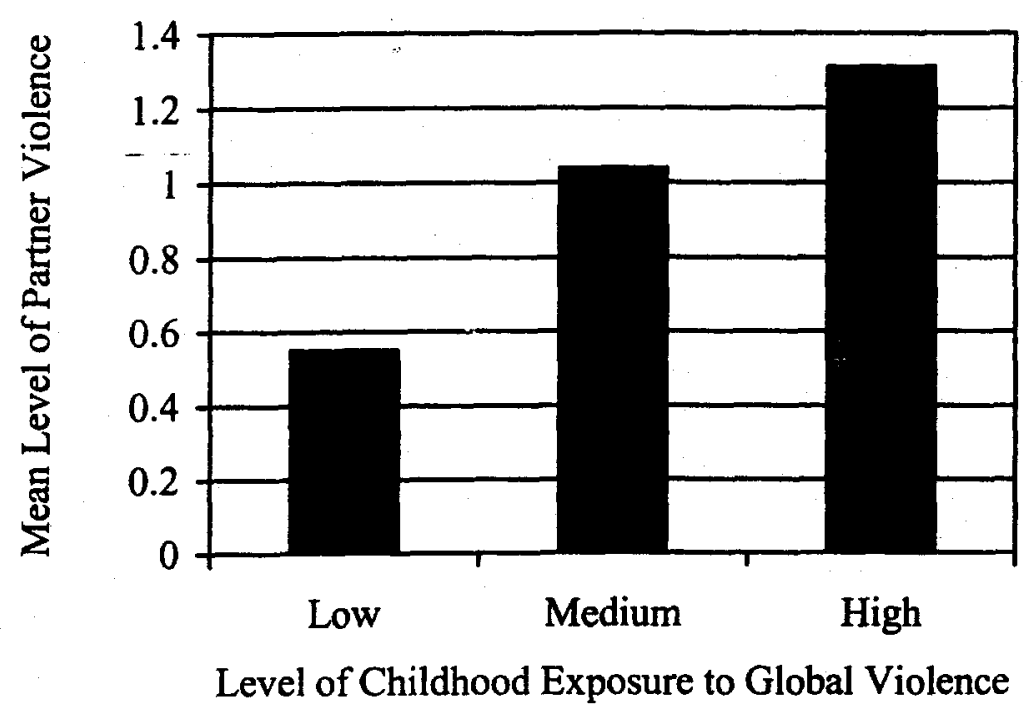

$\frac{1}{3}$

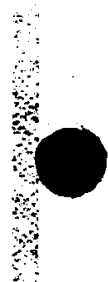

Level of Childhood Exposure to Global Violence 


\section{COMPARING THE EFFECTS OF PHYSICAL CHILD ABUSE AND OBSERVING FAMILY VIOLENCE INTIMATE PARTNER VIOLENCE: MULTIVARIATE ANALYSES}

In the next stage of the analyses, we examine whether exposure to physical child abuse and observing inter-parental violence are independently related to intimate partner violence through a series of Poisson regression models. As previously mentioned, Poisson models are employed after considering the characteristics of the dependent variable, intimate partner violence. Specifically, the distribution of this variable is positively skewed, and limited. ${ }^{18}$ The results for these models are presented in Table 6.1.

The results of a base model predicting partner violence are presented in the first (left hand) column of Table 6.1. The model includes the following variables: age, race, alcohol problems, and regular drug use. The results reveal that age, alcohol problems, and regular drug use are significantly related to partner violence in the predicted direction. Specifically, parolees with more alcohol-related problems, parolees who use illicit drugs regularly, and parolees who are younger are more likely to engage in partner violence. These results are consistent with past research (Duncan et al., 1996).

In the next column (listed under model 1), cumulative or global exposure to violence in the family during childhood is introduced to assess whether it is related to partner violence perpetration when other risk factors (alcohol problems, etc) are statistically controlled. Recall that exposure to violence during childhood is expected to give rise to several negative outcomes (e.g. substance abuse). Thus, it is important to examine whether exposure to violence during -childhood is related to partner violence perpetration over and above its effects on other outcomes, such as drug abuse. The results displayed in the second column of Table 6.1 reveal

${ }^{18}$ The results of the poisson regression are similar to those obtained using OLS regression. 
that global exposure to violence during childhood is not a significant predictor of male perpetrated intimate partner violence in adulthood when other influences are controlled. As in the base model, partner violence is significantly related to age, and regular illicit drug use. Younger parolees and those who use more illicit drugs regutarly have a greater likelihood of partner violence. The results are similar from the base model, but the effects of drug use is somewhat attenuated, and alcohol problems diminishes to non-significance.

Based on our earlier results reported in Figures 6.1 through 6.5, there are at least two explanations to account for the finding that childhood exposure to violence is unrelated to adult partner violence. First, exposure to violence during childhood has several negative consequences (e.g., substance abuse) and a large part of its effects on partner violence operate indirectly through other influences. Second, distinct experiences with exposure to violence during childhood are differentially related to partner violence perpetration. Thus, it is important to disentangle the independent effects of unique experiences with violence.

In the next model (listed in the third column under model 2), exposure to physical child abuse is entered to examine its independent effects on intimate partner violence perpetration in adulthood. The results from this analysis are virtually unchanged from previous models. Experiencing physical abuse in childhood does not-increase the likelihood of partner violence perpetration in adulthood among male parolees in this sample. The results reveal that partner violence is significantly related to, alcohol problems, and regular drug use.

The results from a model examining the independent effects of observing inter-parental violence on partner violence perpetration in adulthood is reported in the fourth column of Table 6.1. The findings offer a stark contrast to our previous results. Observing inter-parental violence 
during childhood surfaces as a strong predictor of intimate partner violence in adulthood even when other risk factors are controlled.

Additionally, the effects of observing partner violence during childhood appear (like the global measure of violence) to reduce the criminogenic effects of alcohol problems in the model. While age and illicit drug use still remain as significant predictors of partner violence, alcohol abuse is no longer significantly related to partner violence. In sum, the results from this model highlight the consequences of observing parental violence in childhood, both as a predictor of partner violence perpetration in adulthood and as an influence on alcohol abuse. 
In our final model, we consider whether child abuse and observing partner violence have significant effects on partner violence when both are included in a model. ${ }^{19}$ The results, reported in the last column of Table 6.1, are unchanged from the previous model. Male parolees who are younger, who regularly use illicit drugs, and who observe inter-parental violence during childhood are more likely to engage in intimate partner violence in adulthood. Exposure to physical child abuse during childhood is not significantly related to partner violence perpetration in adulthood when the effects of observing inter-parental violence are also considered. These results are supportive of our expectations. ${ }^{20}$

${ }^{19}$ As expected, exposure to physical child abuse and observing inter-parental violence are significantly correlated $(r=.32, p<.01)$. However, the strength of this relationship suggests that multicollinearity was not problematic in the model.

20 It is also important to consider whether exposure to physical child abuse and observing interparental violence interact to affect partner violence in adulthood. We estimated one final model that included standardized measures for exposure to physical child abuse and observing interparental violence as well as their product term (i.e., interaction term) as predictors. The results revealed that exposure to physical child abuse and observing inter-parental violence did not interact to increase the likelihood of partner violence in adulthood. 
Table 6.1 - Poisson regression models predicting intimate partner violence in the year prior to incarceration

\begin{tabular}{|c|c|c|c|c|c|}
\hline Variable & Base & Model 1 & Model 2 & Model 3 & Model 4 \\
\hline Age & $-.014^{*}$ & $-.021 * *$ & $- . 0 \longdiv { 4 ^ { * } }$ & $-.019 * *$ & $-.018^{* *}$ \\
\hline Race & -.190 & -.186 & -.199 & -.113 & -.168 \\
\hline Alcohol problems & $.039 * *$ & .029 & $.040 * *$ & .024 & .025 \\
\hline Regular Drug Use & $.136^{*}$ & $.121^{*}$ & $.138^{*}$ & $.113^{*}$ & $.137^{*}$ \\
\hline Global Violence & - & .021 & $--\cdot$ & -- & - \\
\hline Child Abuse & -- & -- & .003 & -- & -.045 \\
\hline Parents' Violence & -- & - & - & $.047^{* *}$ & $.077^{* *}$ \\
\hline Model $\chi^{2}$ & $18.1^{* *}$ & $21.8^{* *}$ & $15.8 * *$ & $28.9 * *$ & $30.0 * *$ \\
\hline
\end{tabular}


While the results from our multivariate analyses suggest that exposure to physical child abuse is not a salient predictor of partner violence, this does not necessarily mean that physical child abuse is not consequential. Rather, it might simply highlight that certain relationships between early exposure to violence and subsequent partner violence perpetration are stronger or more magnified. In short, we do not view these relationships in discrete either/or terms but rather we view them probabilistically in which differences in the effects of exposure to physical child abuse and observing inter-parental violence reflect differences in degree. To illustrate this issue further we examine specific bivariate relationships between these two types of exposure to violence and intimate partner violence in adulthood for respondents with varying levels of exposure (high, medium, and low) during childhood. The results of one-way ANOVAs are displayed in Figure 6.6.

The results clearly reveal that greater exposure to different types of violence in childhood is associated with higher mean levels of partner violence in adulthood. While the general form of the relationships is similar across types of exposure, the results are most magnified for observing inter-parental violence, which is consistent with our multivariate findings. Not surprisingly therefore, observing inter-parental violence in childhood is the only comparison that reveals a statistically significant difference in mean levels of partner violence in adulthood across respondents with varying levels of exposure (high medium, and low) to partner violence in childhood $(\mathrm{F}=4.91, \mathrm{p}<.01)$.

Thus, these results suggest that observing inter-parental violence during childhood has strong and statistically significant effects on intimate partner violence in adulthood even though other relationships appear substantive. Combining these influences into a global index of 
exposure to violence in childhood could lead one to fail to reject the null hypotheses of there being no differences in mean levels of partner violence perpetration (in adulthood) across groups.

Clearly, such a conclusion would be in incorrect because the criminogenic influences of observing inter-parental violence would be masked. In sum, these results highlight the importance of isolating the independent effects of specific types of exposure to violence during childhood.

8

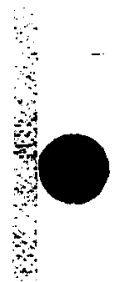


Figure 6.6 - The Relationship Between Different Types of Childhood Exposure to Violence and Intimate Partner Violence
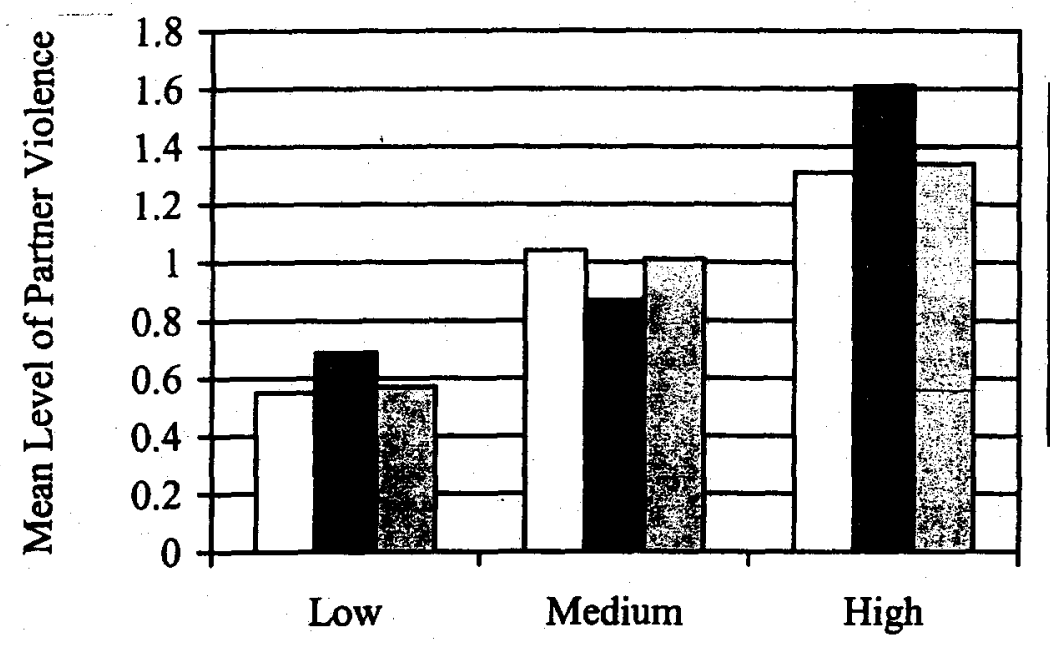

$\square$ Global Violence

$(\mathrm{F}=2.27, \mathrm{p}>.05)$

O Observe Violence

$(\mathrm{F}=4.91, \mathrm{p}<.01)$

$\square$ Child Abuse

$(\mathrm{F}=1.63, \mathrm{p}>.05)$

Level of Early Childhood Violence 


\section{CHAPTER SUMMARY}

This chapter examined the consequences associated with being exposed to violence during childhood. In a series of analyses, it was revealed that exposure to violence during childhood has a series of negative consequences for individuals across the lifecourse.

Additionally, the results illustrate that the cumulative exposure to violence has greater negative consequences for the respondents in the sample.

In a series of regression models predicting intimate partner violence, we assessed whether exposure to physical child abuse as opposed to observing family violence had independent effects on intimate partner violence. The results reveal that observing partner violence during childhood was a more salient influence on intimate partner violence, while controlling for other influences. Finally, direct comparisons of the effects of exposure to child abuse during childhood and observing intimate partner violence using analysis of variance techniques revealed statistically significant relationships for the effects of observing partner violence during childhood on intimate partner violence in adulthood only. 


\section{CHAPTER 7: DISCUSSION AND CONCLUSION}

This project examines the linkages between early life experiences and intimate partner violence and includes an application of Moffitt's developmental theory of offending behavior to the intimate partner violence context. Specifically, the project examines four inter-related issues. First, the characteristics associated with high criminal propensity, or life-course persistent offending. Second, the range of negative outcomes associated with early exposure to violence. Third, whether being exposed to physical child abuse as opposed to observing interparental violence in one's family of origin has different consequences on the likelihood of intimate partner violence. Fourth, whether more serious, life course persistent offenders have a higher likelihood of becoming perpetrators of intimate partner violence in adulthood.

This project uses data collected from a sample of parolees and their spouses in Buffalo, New York in 1987 (Blane, Miller, and Leonard, 1987). The respondents were drawn from a stratified random sample of all parolees residing in the greater Buffalo, New York, area between January 1987 and June 1987. Of the 259 subjects sampled, 194 (75\%) agreed to participate in the study.

Criminal history information was gathered from each respondent's pre-sentence investigation report. Information collected in the interview covered several domains, including self-reported delinquency and crime, early exposure to different types of family violence, and drug/alcohol use. Additionally, revised versions of the Conflict Tactics Scale (Straus, 1979, hereinafter CTS) were used to gauge varying forms of intimate partner violence as well as exposure to physical child abuse and observing inter-parental violence in childhood. 
To assess intimate partner violence, the CTS was given to parolees who were either in a relationship in the year prior to their most recent incarceration or in the three prior months prior to being interviewed. Those parolees who were in relationships during both time periods were given a separate CTS schedule for each relationship.

The sub-sample of the larger study used for the present analyses consists of 180 male parolees, of whom 111 were in a relationship in the year prior to their incarceration, and 107 were in a relationship in the three months prior to the interview.

The overall results of the study include the following. First, life course persistent offenders experience higher levels of social adversity while growing up, involving increased family disruption, having parents with alcohol problems, and higher levels of exposure to violence in the home as compared to non-LCP offenders. Second, life course persistent offenders experience more negative life outcomes than non-LCP offenders including greater lifetime alcohol problems, more illicit drug use, higher levels of violent crime, and higher levels of intimate partner violence in adulthood. Third, early exposure to violence during childhood is associated with a range of negative outcomes such as early delinquent onset, alcohol problems, and violence. Fourth, the effects of early exposure to violence during childhood on perpetrating intimate partner violence in adulthood are influenced primarily by observing inter-parental violence as opposed to being physically abused. Fifth, results from Poisson regression models

- reveals that life course persistent offenders have a higher probability of intimate partner violence in adulthood, net of other influences. Additional salient influences predicting partner violence include drug and alcohol abuse. 
The results from this study illustrate the range of negative consequences associated with exposure to violence in the family during childhood and illuminate important areas for public policy consideration.

\section{POLICY CONSIDERATIONS}

This project illustrates a number of areas for consideration for interventions aimed at reducing intimate partner violence in the future. Moffitt's (1993) developmental theory encourages policies that are both preventive and treatment-oriented. For example, to the extent that offending trajectories can be delayed, altered or deflected along the lifecourse, interventions could work to prevent the subsequent development of partner violence. Delaying early delinquent onset is of critical importance in reducing opportunities for criminal escalation toward partner violence. Our results suggest that interventions targeted at reducing social adversity in families, improving parental management skills and reducing alcohol abuse by parents can assist in delaying the early onset of delinquency and the pathway for life-course persistent offending behavior.

Additionally, efforts at developing critical thinking and problem solving skills, enhancing verbal abilities, and providing resistance skill training to increase the abilities of adolescents to resist various criminogenic influences and opportunities would help delay initiation into delinquent behavior. Moreover, the extent to which interventions encourage the development of non-violent means for resolving disputes as well as coping mechanisms for dealing with angry emotional states (Agnew, 1992) would represent demonstrable steps toward reducing incidents of partner violence in the future.

Moffitt's theory also presents opportunities for impacting offending behavior and partner violence by better specifying offender treatment programs. The recent research on typologies of battering behavior (Saunders, 1992; Holtzworth-Munroe and Stuart, 1994) as well as the 
emerging literature on successful rehabilitation efforts (Gendreau and Ross, 1987; Andrews et al., 1990) illustrate the important opportunities for improving and better specifying treatment programs for men who physically assault their partners. Identifying differences across types of offenders who assault their partners, illustrates the benefits of developing interventions targeted at serious offenders. Quite simply, these results suggest that targeting serious offenders for general rehabilitative interventions can have additional benefits, including the reduction of intimate partner violence. While it is clearly the case that serious offenders represent only a subset of all batterers [for example, Holtzworth-Munroe and Stuart (1994) argue that serious offenders comprise approximately one quarter of all batterers], they are likely to have a lengthy criminal history and engage in other forms of serious anti-social behavior including alcohol and drug abuse, as well-as psychological and sexual abuse. Thus, the community wide benefits involved in targeting their antisocial conduct appear far-reaching.

\section{FUTURE DIRECTIONS}

Future research on intimate partner violence should continue to explore the intersections between the general criminal career literature, as well as the relationships between types of offenders and intimate partner violence more generally. Such research will further illuminate the connections between general offending behaviour and partner violence, the range of characteristics associated with partner violence, and the possibilities for effective interventions aimed at reducing this social problem in the future. 


\section{REFERENCES}

Andrews, D., Zinger, I., Hoge, R., Bonta, J., Gendreau, P., \& Cullen, F. (1990). Does correctional treatment work? A clinically relevant and psychologically informed meta-analysis. Criminology, 28: 369-404.

Agnew, R. (1992). Foundation for a general strain theory of crime and delinquency. Criminology, 30: 47-87.

Bachman, R. And Saltzman, L.E. (1995). Violence Against Women: Estimates from the Redesigned Survey (BJS Publication No. 154-348). Washington, DC: U.S. Department of Justice, Bureau of Justice Statistics.

Bamett, O. and Hamberger, L.K. (1992). The assessment of maritally violent men on the California Psychological Inventory. Violence and Victims, 7: 15-22.

Blane, H., Miller, B., and Leonard, K. (1987). Intra- and Intergenerational Aspects of Serious Domestic Violence and Alcohol and Drug Abuse in Buffalo, 1987. ICPSR study number 9984.

Crowell, N. and Burgess, A. (1996). Understanding Violence Against Women. Washington, D.C.: National Academy Press

Dean, C., Brame, R. \& Piquero, A. (1996). Criminal propensities, discrete groups of offenders, and persistence in crime. Criminology, 34; 547-574.

Dutton, D.G. (1988). Profiling of wife assaulters: Preliminary evidence for a trimodel analysis.Violence and Victims, 3: 5-29.

Fagot, B.I. Loeber, R., and Reid, J.B. (1988). Developmental determinants of male-to-female aggression. In G.W. Russell (ed.), Violence in Intimate Relationships. (pps. 91-105), Costa Mesa, CA: PMA Publishing Corp.

Gelles, R. and Loseke, D. (1993). Current Controversies on Family Violence. Newbury Park, CA: Sage.

Gendreau, P., and Ross, R. (1987). Revivification of rehabilitation: Evidence from the 1980s. Justice Quarterly, 4: 349-407.

Gondolf, E. W. (1988). Who are those guys? Toward a behavioral typology of batterers.

Violence and Victims, 3:187-203. 
Hanson, R.K., Cadsky. O. Harris, A., and Lalonde, C. (1997). Correlates of battering among 997 men: Family history, adjustment, and attitudinal differences. Violence and Victims, 12: 191 208.

Holtzworth-Munroe, A. and Stuart, G. L. (1994). Typologies of male batterers: Three subtypes and the differences among them. Psychological Bulletin, 1 16:476-497.

Hotaling, G.T., and Sugarman, D.B. (1986). An analysis of risk markers in husband to wife violence: The current state of knowledge. Violence and Victims, 1: 101-124.

Johnson, H and Sacco, V.F. (1995). Researching violence against women: Statistics Canada's national survey. Canadian Journal of Criminology, 37:281-304.

Kaufman Kantor, G. (1993). Refining the brushstrokes in portraits of alcohol and wife assaults. In Alcohol and Interpersonal Violence: Fostering Multidisciplinary Perspectives. NIH Research Monograph No. 24 (pp.281-290). Rockville, MD: US Department of Health and Human Services.

Kaufman Kantor,G. and Straus, M. A. (1989). Substance abuse as a precipitant of wife abuse victimization. American Journal of Drug and Alcohol Abuse, 15: 173-189.

Laub, J. and Sampson, R. (1993). Turning points in the life course: Why change matters to the study of crime. Criminology, 31: 301-325.

LeBlanc, M. (1990). Two processes of the development of persistent offending: Activation and escalation. In L.N. Robins and M. Rutter (eds.), Straight and Deviant Pathways from Childhood to Adulthood (pp. 82-100). Cambridge, UK: Cambridge University Press.

Loeber, R. (1988). Natural histories of conduct problems, delinquency, and associated substance use. In B.B. Lahey and A.E. Kazdin (eds.), Advances in Clinical Child Psychology, (pp. 73-124). New York: Plenum.

Loeber, R. (1982). The stability of antisocial and delinquent child behavior: A review. Child Development, 53:1431-1446.

Loeber, R. and Dishion, T. (1983). Early predictors of male delinquency: A review. Psychological Bulletin, 94: 68-99.

Mazerolle, P. (1997). Delinquent definitions and participation age: Assessing the invariance hypothesis. Studies on Crime and Crime Prevention, 6: 151-168.

McHenry, P.C., Julien, T.W. and Gavazzi, S. M. (1995). Toward a biopsychological model of domestic violence. Journal of Marriage and the Family, 57:307-320. 
Miller, B.A. (1990). The interrelationships between alcohol and drugs and family violence. In M. De La Rosa, E.Y. Lambert, and B. Gropper (eds.), Drugs and Violence: Causes, Correlates, and Consequences. National Institute on Drug Abuse research Monograph, 103: 177-207.

Miller, B.A., Nochajski, T., Leonard, K., Blane, H., Gondoli, D., and Bowers, P. (1990). Spousal violence and-alcohol/drug problems among parolees and their spouses. Women \& Criminal Justice, 12: 55-72.

Moffitt, T. (1993). Adolescent-limited and life-course persistent antisocial behavior: A developmental taxonomy. Psychological Review, 100:674-701.

Moffitt, T., Caspi, A., Dickinson, N., Silva, P., \& Stanton, W. (1996). Childhoodonset versus adolescent-onset antisocial conduct problems in males: Natural history from ages 3 to 18 years. Development and Psychology, 8: 339-424.

Paternoster, R. and Brame, R. (1997). Multiple routes to delinquency? A test of developmental and general theories of crime. Criminology, 35: 49-84.

Paternoster, R., Dean, C., Piquero, A., Mazerolle, P., and Brame, R. (1997). Generality, continuity, and change in offending. Journal of Quantitative Criminology, 13: 231-266.

Patterson, G. DeBaryshe, B., and Ramsey, E. (1989). A developmental perspective on antisocial behavior, American Psychologist, 44: 329-335.

Patterson, G., and Yoerger, K. (1993). Developmental models for delinquent behavior. In S. _Hodgins (ed.), Mental Disorder and Crime (pp. 140-172). Newbury Park, CA: Sage.

Saunders, D.G. (1992). A typology of men who batter: Three types derived from cluster analysis. American Journal of Orthopsychiatry, 62: 264-275.

Simons, R. Wu, C. Johnson, C, and Conger, R. (1995). A test of various perspectives on the intergenerational transmission of domestic violence, Criminology 331: 141-172.

Smith, C., Lizotte, A., Thomberry, T., \& Krohn, M. (1995). Resilient youth:

Identifying factors that prevent high-risk youth from engaging in delinquency and drug use. In Z. Smith Blau and J. Hagan (eds.), Current perspectives on aging and the lifecycle: Delinquency and disrepute in the life course (pp. 217-247). Greenwich, CT: JAI Press, Inc.

Stark, E., and Flitcraft, A. (1995). Spouse abuse. In J.M. Last \& R.B. Wallace (eds.). Public health and preventive medicine (13th ed., pp. 1040-1043). Norwalk, CT: Appleton \& Lange. 
Straus, M.A. (1979). Measuring intrafamily conflict and violence: The conflict tactic (CT) scale. Journal of Marriage and the Family, 41: 75-88.

Straus, M.A., and Gelles, R.J. (1990). Physical Violence in American Families: Risk Factors and Adaptations to Violence in 8,145 Families. New Brunswick, NJ: Transaction.

Thornberry, T. (1987). Toward an interactional theory of delinquency. Criminology, 25: 863-891.

Thomberry, T. (1997). Developmental theories of crime and delinquency. In T. Thomberry (ed.), Advances in Criminological Theory, Vol. 7. New Brunswick, NJ: Transaction.

Tolan, P. H. (1987). Implications of age of onset for delinquency risk. Journal of Abnormal Child Psychology, 15: 47-65.

Werner, E.E. (1984). Resilient children, Young Children, 40: 68-72.

Werner, E.E. (1989). High risk children in young adulthood: A longitudinal study from birth to 32 years, American Journal of Orthopsychiatry, 59: 72-81. 


\section{APPENDIX A - Measures}

\section{Measures of Exposure to Violence (Child Abuse and Observing Inter-Parental Violence) During Childhood}

During an average year in respondent's childhood, how often did respondent's parents perpetrate the following acts towards the respondent (child abuse) or to each other (inter-parental violence)

Kicked, bit, hit with fist

Hit with something

Beat up

Burned/scalded

Choked

Threatened with knife/gun

Used knife or gun

Threaten to hit/throw at

Threw/smashed/hit/kicked something

Threw something at spouse/child

Pushed/grabbed/shoved

Slapped

\section{Measures of Intimate Partner Violence in Adulthood}

\section{In Year Prior to Prison}

In the year prior to prison, how often the respondent perpetrated the following acts towards their partner:

Kicked, bit, hit with fist

Hit with something

Beat up

Burned/scalded

Choked

Threatened with knife/gun

Used knife or gun

Forced sex

Slapped 
In the Three Months Prior to Interview

Kicked, bit, hit with fist

Hit with something

Beat up

Burned/scalded

Choked

Threatened with knife/gun

Used knife or gun

Forced sex

Slapped

\section{Early Delinquent Onset}

At what age did respondent: (Classified as "early onset" if engaged in any of the acts prior to 13 years of age)

Take something from a store or business during business hours without paying for it? Enter a store after business hours or a home in order to steal things?

Tried to get money from a person or business by threatening them in some manner? Physically assaulted another person?

\section{Violent Crime (Self-reported incidence)}

Whether or not the respondent had ever:

Take anything of value from someone, using a weapon?

Tried to get money from a person or business by threatening them in some manner?

Kidnapped, or held anyone against their will?

Physically assaulted another person?

Attempted or had sexūal intercourse or other sexual acts through the use of force?

\section{Illicit Drug Use}

- Whether or not respondent reported using marijuana, cocaine, heroin, speed, downers, or LSD at least once per week for a month. 


\section{Alcohol Problems}

Respondents were asked whether or not they experienced any of these alcohol-related problems:

Has your family objected because you were drinking too much?

Do you ever think you were an excessive drinker?

Have you ever drunk a fifth of liquor in one day?

Has there ever been a period of two weeks when every day you were drinking at least seven drinks?

Have friends, your doctor, your clergyman, or any other professional ever said you were drinking too much?

Have you ever wanted to stop drinking but couldn't?

Some people promise themselves not to drink before 5. 'clock or never to drink alone in order to control their drinking. Have you ever done anything like that?

Have you ever had job or school trouble because of drinking?

Did you ever lose a job (or get kicked out of school) because of drinking?

Have you ever gotten into trouble driving because of drinking?

Have you ever been arrested because of drinking, or for disturbing the peace while drinking?

Have you ever gotten into physical fights while drinking?

Have you ever gone on binges or benders where you kept drinking for a couple of days or more without sobering up?

Did you neglect some of your usual responsibilities while on binges/benders?

Have you ever had bad blackouts while drinking?

Do you ever need drink when get up in the morning?

Have you ever had the shakes after stopping or cutting down on drinking?

_._. Have you ever had fits/seizures after stopping or cutting down on drinking?

Have you ever had the DT's when you quit drinking?

Have you ever continued to drink when you knew you had a serious illness that might be made worse by drinking?

Has there been a period in your life when you could not do your ordinary work well unless you had something to drink?

\section{Negative Life Events}

Number of households lived in prior to age 18 (more than four $=1$ )

Parents separated (yes $=1$ )

Parents divorced (yes $=1$ )

Experienced death (yes $=1$ )

Lived in foster home (yes $=1$ )

Total unique parental figures (more than $2=1$ ) 


\section{Paternal Alcohol Problems}

Maternal Alcohol Problems

$$
\begin{aligned}
& \alpha=.79 \\
& \alpha=.83
\end{aligned}
$$

Paternal Alcohol Problems

The same questions were asked for both the respondent's father and mother.

Did friends or family members think (s)he drank too much?

Did (s)he ever lose friends because of drinking?

Did his/her drinking ever cause problems with his work, like missing work or losing a job?

Did (s)he ever have any legal problems as a result of her drinking, like being arrested or losing his/her driver's license?

Did (s)he ever have any problems with his/her health, like D.T.'s liver cirrhosis, blackouts, or stomach problems from drinking?

Was (s)he ever for alcoholism, such as with antabuse, being hospitalized, or attending Alcoholics Anonymous? 
National Criminal Justice Reference Service (NCJRS) Box 6000

Rockville, MD 20849-6000

\section{APPENDIX B - Agreement Between Parolee's and Their Partners Using the Conflict Tactics Scale for Violence in the Past Three Months}

\begin{tabular}{|c|c|c|c|c|c|}
\hline Variable & $\begin{array}{l}\text { Agree (Yes } \\
\text { event) }\end{array}$ & $\begin{array}{c}\text { Agree (No } \\
\text { event) }\end{array}$ & $\begin{array}{c}\text { Parolee yes / } \\
\text { Partner no }\end{array}$ & $\begin{array}{c}\text { Partner yes / } \\
\text { Parolee no }\end{array}$ & TOTAL \\
\hline $\begin{array}{l}\text { KCT } 11 \\
\text { (threaten to hit) }\end{array}$ & $\begin{array}{c}10 \\
(11 \%)\end{array}$ & $\begin{array}{c}42 \\
(48 \%)\end{array}$ & $\begin{array}{c}20 \\
(23 \%)\end{array}$ & $\begin{array}{c}16 \\
(18 \%)\end{array}$ & 88 \\
\hline $\begin{array}{l}\text { KCT12 } \\
\text { (threw/smash something) }\end{array}$ & $\begin{array}{c}14 \\
(16 \%)\end{array}$ & $\begin{array}{c}42 \\
(48 \%) \\
\end{array}$ & $\begin{array}{c}16 \\
(18 \%)\end{array}$ & $\begin{array}{c}16 \\
(18 \%)\end{array}$ & 88 \\
\hline $\begin{array}{l}\text { KCT13 } \\
\text { (threw at spouse) }\end{array}$ & $\begin{array}{c}2 \\
(2 \%)\end{array}$ & $\begin{array}{c}73 \\
(83 \%) \\
\end{array}$ & $\begin{array}{c}4 \\
(5 \%)\end{array}$ & $\begin{array}{c}9 \\
(10 \%)\end{array}$ & 88 \\
\hline $\begin{array}{l}\text { KCT14 } \\
\text { (push/grab/shove) }\end{array}$ & $\begin{array}{c}16 \\
(18 \%)\end{array}$ & $\begin{array}{c}40 \\
(46 \%) \\
\end{array}$ & $\begin{array}{c}16 \\
(18 \%)\end{array}$ & $\begin{array}{c}16 \\
(18 \%)\end{array}$ & 88 \\
\hline $\begin{array}{l}\text { KCT15 } \\
\text { (slap) }\end{array}$ & $\begin{array}{c}10 \\
(9 \%)\end{array}$ & $\begin{array}{c}57 \\
(65 \%) \\
\end{array}$ & $\begin{array}{c}7 \\
(8 \%)\end{array}$ & $\frac{14}{(16 \%)}$ & 88 \\
\hline $\begin{array}{l}\text { KCT16 } \\
\text { (kick/hit/punch) }\end{array}$ & $\begin{array}{c}2 \\
(2 \%)\end{array}$ & $\begin{array}{c}67 \\
(76 \%)\end{array}$ & $\begin{array}{c}7 \\
(8 \%)\end{array}$ & $\begin{array}{c}12 \\
(14 \%)\end{array}$ & 88 \\
\hline $\begin{array}{l}\text { KCT17 } \\
\text { (hit w/ something) }\end{array}$ & $\begin{array}{c}0 \\
(0 \%)\end{array}$ & $\begin{array}{c}80 \\
(91 \%)\end{array}$ & $\begin{array}{c}0 \\
(0 \%)\end{array}$ & $\begin{array}{c}8 \\
(9 \%)\end{array}$ & 88 \\
\hline $\begin{array}{l}\text { KCT18a } \\
\text { (beat up) }\end{array}$ & $\begin{array}{c}0 \\
(0 \%)\end{array}$ & $\begin{array}{c}72 \\
(82 \%) \\
\end{array}$ & $\begin{array}{c}6 \\
(7 \%)\end{array}$ & $\begin{array}{c}10 \\
(9 \%)\end{array}$ & 88 \\
\hline $\begin{array}{l}\text { KCT18b } \\
\text { (burned/scalded) }\end{array}$ & $\begin{array}{c}0 \\
(0 \%)\end{array}$ & $\begin{array}{c}88 \\
(100 \%) \\
\end{array}$ & $\begin{array}{c}0 \\
(0 \%) \\
\end{array}$ & $\begin{array}{c}0 \\
(0 \%)\end{array}$ & 88 \\
\hline $\begin{array}{l}\text { KCT20 } \\
\text { (choked) }\end{array}$ & $\begin{array}{c}0 \\
(0 \%)\end{array}$ & $\begin{array}{c}75 \\
(85 \%) \\
\end{array}$ & $\begin{array}{c}5 \\
(6 \%)\end{array}$ & $\begin{array}{c}8 \\
(9 \%)\end{array}$ & 88 \\
\hline $\begin{array}{l}\text { KCT22 } \\
\text { (use knife/gun) }\end{array}$ & $\begin{array}{c}0 \\
(0 \%)\end{array}$ & $\begin{array}{c}88 \\
(100 \%) \\
\end{array}$ & $\begin{array}{c}0 \\
(0 \%)\end{array}$ & $\begin{array}{c}0 \\
(0 \%)\end{array}$ & 88 \\
\hline $\begin{array}{l}\text { KCT23 } \\
\text { (forced sex) }\end{array}$ & $\begin{array}{c}0 \\
(0 \%)\end{array}$ & $\begin{array}{c}83 \\
(94 \%) \\
\end{array}$ & $\begin{array}{c}1 \\
(1 \%)\end{array}$ & $\begin{array}{c}4 \\
(5 \%)\end{array}$ & 88 \\
\hline TOTAL & $\begin{array}{c}54 \\
(5 \%) \\
\end{array}$ & $\begin{array}{c}807 \\
(76 \%) \\
\end{array}$ & $\begin{array}{c}82 \\
(8 \%)\end{array}$ & $\begin{array}{c}113 \\
(11 \%)\end{array}$ & 1056 \\
\hline
\end{tabular}

